\title{
Assessing abortion-related experiences and needs in four districts of Maharashtra and Rajasthan, 2006
}

Shireen J. Jejeebhoy

Population Council

A.J. Francis Zavier

Population Council

Shveta Kalyanwala

Population Council

Follow this and additional works at: https://knowledgecommons.popcouncil.org/departments_sbsr-pgy

Part of the Demography, Population, and Ecology Commons, Family, Life Course, and Society Commons, Gender and Sexuality Commons, International Public Health Commons, Medicine and Health Commons, Obstetrics and Gynecology Commons, and the Women's Health Commons How does access to this work benefit you? Let us know!

\section{Recommended Citation}

Jejeebhoy, Shireen J., A.J. Francis Zavier, and Shveta Kalyanwala. 2010. "Assessing abortion-related experiences and needs in four districts of Maharashtra and Rajasthan, 2006." New Delhi: Population Council. 


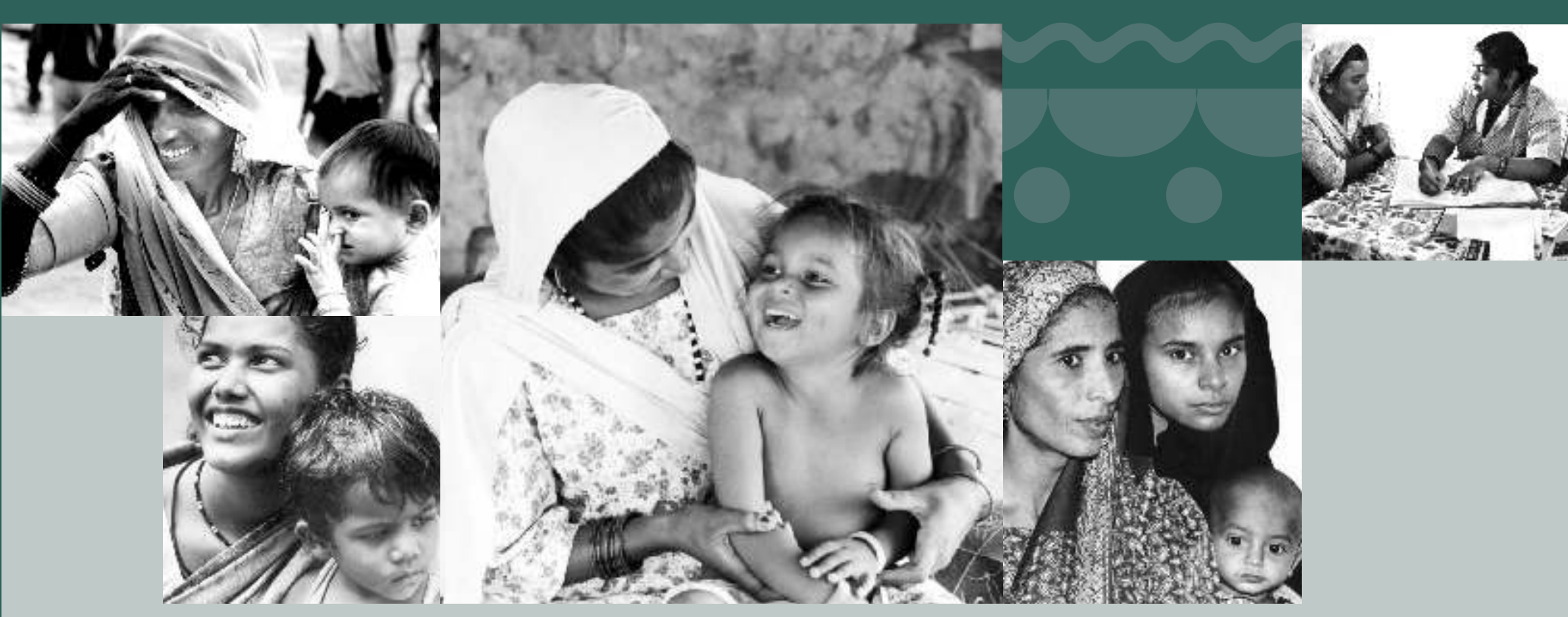

\section{Assessing abortion-related experiences and needs in four districts of Maharashtra and Rajasthan, 2006}


This report is the result of a collaborative project undertaken by a consortium of organisations - including Ipas, the Federation of Obstetrics and Gynaecological Societies of India (FOGSI), the Family Planning Association of India (FPAI), the Centre for Enquiry into Health and Allied Themes (CEHAT), Action Research and Training (ARTH), the Population Council, the Society of Midwives, India (SOMI) and Uppsala University - to explore ways of enabling rural women to acquire accessible and high quality abortion services. A comprehensive and evidence-based abortion care model suitable for rural women was developed and implemented in one district of a more developed state - Aurangabad, in Maharashtra - and one district of a lesser developed state, namely, Tonk in Rajasthan. Prior to its implementation, the Population Council conducted a baseline assessment of rural women's abortion-related perceptions and experiences.

For additional copies of this report, please contact:

Population Council

Zone 5-A, Ground Floor

India Habitat Centre

Lodi Road

New Delhi 110003

Phone: 011-2464 2901/02

email: info-india@popcouncil.org

Web site: http://www.popcouncil.org/asia/india.html

The Population Council is an international, non-profit, non-governmental organisation that seeks to improve the wellbeing and reproductive health of current and future generations around the world and to help achieve a humane, equitable and sustainable balance between people and resources. The Council conducts biomedical, social science and public health research, and helps build research capacities in developing countries.

Copyright (C) 2010 Population Council

Suggested citation: Jejeebhoy, S. J., A. J. F. Zavier and S. Kalyanwala. 2010. Assessing abortion-related experiences and needs in four districts of Maharashtra and Rajasthan, 2006. New Delhi: Population Council. 


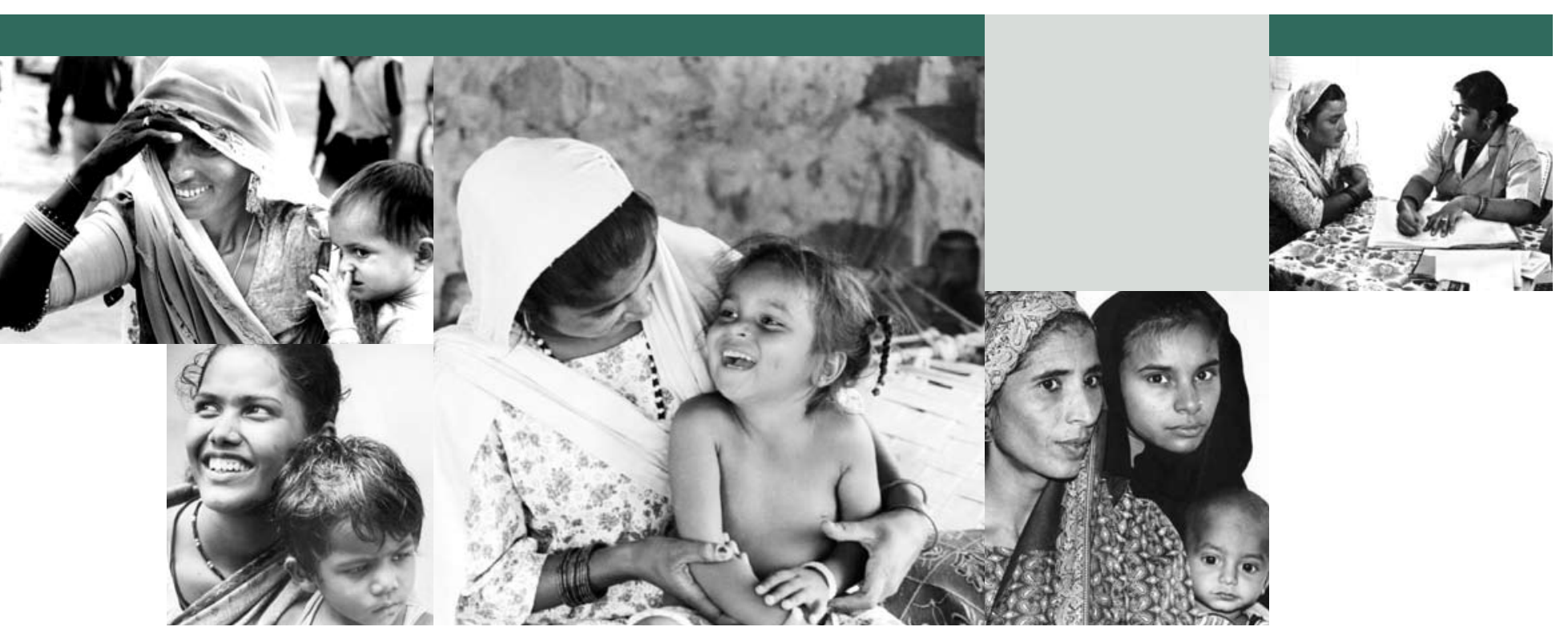

\section{Assessing abortion-related experiences and needs in four districts of Maharashtra and Rajasthan, 2006}

Shireen J. Jejeebhoy

A J Francis Zavier

Shveta Kalyanwala

Population Council 



\section{Contents}

List of tables $\quad \mathrm{v}$

Acknowledgements vii

Chapter 1: Introduction 1

$\begin{array}{ll}\text { Rationale } & 1\end{array}$

Study objectives $\quad 1$

Background 2

Settings $\quad 3$

Study design $\quad 5$

Sampling $\quad 5$

Data collection and analysis $\quad 7$

$\begin{array}{ll}\text { Sample coverage } & 7\end{array}$

$\begin{array}{ll}\text { Structure of this report } & 8\end{array}$

Chapter 2: Social and demographic characteristics of households and respondents 9

Characteristics of households 9

$\begin{array}{ll}\text { Characteristics of respondents } & 10\end{array}$

Awareness and practice of contraception $\quad 12$

Chapter 3: Awareness of and perceptions about abortion 14

Awareness of abortion methods $\quad 14$

$\begin{array}{ll}\text { Facilities providing abortion services } & 14\end{array}$

Legal issues relating to abortion $\quad 17$

Attitudes about the conditions under which abortion should be permitted $\quad 18$

Sources of information about abortion 19

Women's own preferences in selecting an abortion provider and facility 19

$\begin{array}{ll}\text { Sex-determination and sex-selective abortion } & 21\end{array}$

Chapter 4: Prevalence of induced abortion 23

Induced abortion levels: lifetime and recent 23 
Abortion-related decision-making

Experience of second-trimester abortion

Experience of multiple abortion

Providers from whom abortion was sought

Sources of information about provider

Cost of services

Quality of care

Post-abortion morbidity

Post-abortion contraception

Chapter 6: Summary and conclusions

Knowledge about abortion

Awareness of abortion facilities and providers

Knowledge of the legality of abortion

Sources of abortion-related information

Preferences in selecting an abortion facility

Sex-selective abortion

Levels of abortion

Experience of second-trimester abortion

Repeat abortions

Abortion procedures and providers

Quality of care

Post-abortion morbidity

Post-abortion contraception

Recommendations 


\section{List of tables}

Table 1.1: Socio-demographic characteristics of study districts and states, 2000s 4

Table 1.2: $\quad$ Coverage of the study 8

Table 2.1: $\quad$ Characteristics of households 10

Table 2.2: $\quad$ Socio-demographic profile of respondents 11

Table 2.3: $\quad$ Percentage of women who reported awareness of various contraceptive methods and practice of family planning 13

Table 3.1: $\quad$ Awareness of abortion methods: Percentage of women who reported awareness $\begin{array}{ll}\text { of methods of safe abortion } & 14\end{array}$

Table 3.2: $\quad$ Awareness of facilities providing abortion: Percentage of women who reported $\begin{array}{ll}\text { awareness of facilities providing abortion } & 15\end{array}$

Table 3.3: Perceptions about community access to abortion: Percent distribution of women by perceptions about where women in the community access abortion

Table 3.4: $\quad$ Awareness of legal issues related to abortion: Percentage of women by misperceptions held about the legality of abortion and awareness of at least one situation in which abortion is legal

Table 3.5: Abortion related attitudes: Percentage of women by attitudes about the acceptability of abortion in various situations

Table 3.6: $\quad$ Sources of information: Percentage of women who obtained information on abortion from various sources

Table 3.7: Perceptions about preferred abortion providers: Percentage of women reporting the provider from whom they would seek abortion in case of an unwanted pregnancy

Table 3.8: $\quad$ Key factors selecting an abortion facility and provider: Percentage of women by factors perceived to be important in selecting a facility and provider for abortion

Table 3.9: $\quad$ Awareness of sex-selective abortion: Percent distribution of women by awareness of sex-selective abortion and its prevalence in their community

Table 4.1: Lifetime and recent abortion: Percentage of women by prevalence of lifetime and recent induced abortion

Table 4.2: $\quad$ Prevalence of lifetime and recent abortions by background characteristics of women

Table 5.1: Abortion-related decision-making: Percentage of women by person(s) making decision about abortion and selection of a successful abortion provider 
Table 5.2: Timing of abortion: Percentage of women reporting a second-trimester abortion by background characteristics

Table 5.3: $\quad$ Experience of multiple abortions: Percentage of women reporting multiple abortions by background characteristics

Table 5.4: Providers from whom abortion was sought: Percentage of women by individual from whom abortion was sought (successfully or unsuccessfully) and number of providers approached for abortion

Table 5.5: Termination of pregnancy: Percentage of women by individual who conducted the abortion, method used and time taken to reach the facility where the pregnancy was successfully terminated

Table 5.6: $\quad$ Source(s) of information about the abortion provider: Percentage of women by sources of information on successful abortion provider (trained or untrained)

Table 5.7: Cost of abortion services: Percent distribution of women by costs incurred for the abortion procedure

Table 5.8: Quality of care provided by the successful provider: Percentage of women by indicators of quality of abortion-related care obtained

Table 5.9: $\quad$ Post-abortion morbidity: Percentage of women by post-abortion morbidity experienced

Table 5.10: Post-abortion contraception: Percentage of women by post-abortion contraceptive practice

Table 5.11: Counselling for post-abortion contraception: Percentage of women reporting post-abortion contraception by counselling status, sex combination of living children and background characteristics

Appendix 1: Socio-demographic profile of respondents, respondent awareness and attitudes about abortion-related matters

Appendix 2: Abortion-related decision making, women who had ever experienced abortion, by district

Appendix 3: Abortion experiences, women who had ever had an abortion and those who had an abortion in the 5 years prior to the interview, by district

Appendix 4: Quality of abortion care excludes previous unsuccessful attempts 


\section{Acknowledgments}

The Population Council is a member of the Consortium for Safe Abortions in India. The study was undertaken on behalf of the Consortium, jointly funded by The Swedish International Development Cooperation Agency (SIDA) and the David and Lucile Packard Foundation. Members are Action Research \& Training for Health (ARTH); Center for Enquiry into Health and Allied Themes (CEHAT); Federation of Obstetric and Gynecological Societies of India (FOGSI); FPA India; International unit of Maternal Child Health (IMCH)-Uppsala University; Ipas and Indian Society of Mid-wives.

We would like to acknowledge the support received from Consortium members in undertaking this study. In addition, we are grateful to Sushanto Banerjee and Rajib Acharya for their insightful suggestions and inputs during the design and analysis phase of the study; Jyoti Moodbidri and Komal Saxena for editing the report so ably and for their careful attention to detail; MA Jose and Komal Saxena for administrative and technical support at all stages of the study; and our team of investigators for their painstaking efforts in

collecting the data. Finally, we would like to thank all of the women who participated in the study and shared their experiences and insights with us so willingly. 



\section{CHAPTER 1}

\section{Introduction}

\section{Rationale}

For more than 30 years, following the enactment of the Medical Termination of Pregnancy (MTP) Act of 1971, women in India have been entitled to legal abortion services in registered facilities and by certified providers (Chhabra and Nuna, 1994; Government of India, 1971). Women are entitled to abortions across a range of situations: when the mother's life is at risk or when her physical or mental health is compromised; in case of rape, if the pregnancy is likely to result in the birth of a child with physical or mental abnormalities and if the pregnancy was the result of contraceptive failure. Abortions may be performed up to 20 weeks of gestation and the consent of the husband or guardian is not required for adult women. With these liberal conditions, the MTP Act was intended to reduce the incidence of illegal abortions. However, most women continue to obtain services outside of registered settings, and/or from uncertified and often unqualified providers. It is estimated that most of the estimated 6.7 million abortions that are performed in India each year are illegal (Chhabra and Nuna, 1994). Moreover, abortions performed by uncertified providers are estimated to be 2 to 10 times higher than those performed legally by physicians (Ganatra, 2000), and hold potentially serious adverse consequences for women's health. Indeed, complications arising from abortion contribute to some 8 percent of maternal deaths (Registrar General, India, 2006).

Women's access to safe abortion services from public sector facilities is limited by a range of supply and demand side factors. On the supply side, abortion services are rarely available at Primary Health Centre (PHC) level or in rural areas; most PHCs and even some Community Health Centres (CHCs) lack trained staff and the required equipment and supplies for providing safe abortions (Barge et al., 1998; Kalyanwala et al., 2010) or do not have the necessary certification. On the demand side, there are a number of factors at the individual and community levels that may inhibit women from seeking abortion in public sector facilities (see, for example, Elul et al., 2004; Malhotra et al., 2003; Ganatra et al., 2008). These include limited understanding of the legality of abortion, reluctance to obtain services from clinics known to provide abortion services, lack of awareness about the need to seek abortion early in pregnancy, poor perceived quality of care, lack of confidentiality and the frequent insistence on concurrent family planning (Ganatra, 2000; Barua, 2007; Elul et al., 2004). Indeed, significant numbers of women-one-fifth in a study in Rajasthan-used a home remedy or obtained services from an informal provider in an attempt to terminate their pregnancy; most of these were unsuccessful, leading women to seek services eventually —often in the second trimester-from the formal sector (Elul et al., 2004).

\section{Study objectives}

Recognizing the urgent need to enable rural women to acquire accessible and high quality abortion services, a consortium of organisations-including 
Ipas, the Federation of Obstetrics and Gynaecological Societies of India (FOGSI), the Family Planning Association of India (FPAI), the Centre for Enquiry into Health and Allied Themes (CEHAT), Action Research and Training (ARTH), the Population Council, the Society of Midwives, India (SOMI) and Uppsala University-has come together with the goal of increasing access to legal, safe, and comprehensive abortion services, including postabortion family planning, in the public health system, especially among the rural poor. One of its key activities was to develop a comprehensive and evidence-based abortion care model suitable for rural women. The model, which aims to address both supply and demand side barriers, focuses on enabling public sector sites to offer comprehensive abortion care services and simultaneously, to build awareness among and empower poor rural women to access safe and quality abortion services. The model has been implemented in one district of a more developed state-Aurangabad, in Maharashtra-and one district of a lesser developed state, namely, Tonk in Rajasthan.

Prior to initiating the comprehensive abortion care model, baseline research was conducted to document facility-level readiness to provide abortion services as well as the perspectives and experiences of women residing in the intervention districts, namely Aurangabad and Tonk in Maharashtra and Rajasthan, respectively. Baseline findings of the supply side investigation have been presented elsewhere (Kalyanwala et al., 2010).

The aim of this report is to shed light on community-level perspectives about abortion services and probe the experiences of women who had undergone abortion. More specifically, it provides baseline information on these abortion-related issues in one district each of Maharashtra and Rajasthan (Aurangabad and Tonk) prior to the implementation of the comprehensive abortion care model in these districts, as well as in corresponding control districts, namely Jalna in Maharashtra and Bundi in Rajasthan. Our investigation aims to better understand women's awareness of and attitudes about abortion and their perceptions about the quality of care received, including in public sector facilities. It also aims to probe the experiences of women who had undergone abortion; the timing of their abortion, provider choice and factors underlying this choice, the number of providers from whom abortion was sought, whether husband's consent was mandatory, whether contraception was made a condition for abortion, the extent of contraceptive counselling and so on.

\section{Background}

Efforts at collecting primary data on abortion in India have been largely restricted to women who have sought abortion in clinical settings. There are, in contrast, few population-based studies that focus on abortion. While the NFHS-2 attempted to assess whether women had ever experienced abortion, this assessment relied on a single question "Did you ever have an induced abortion?". Findings suggest considerable under-reporting: just $2 \%$ reported an abortion over the course of their married life (IIPS and ORC Macro, 2000). However, three notable studies conducted over the last decade have shed light on the prevalence of abortion and the 
experiences of women who underwent abortion using more detailed probing (Malhotra et al., 2003; Elul et al., 2004; Ganatra et al., 2008). Findings indicate considerable variation in the proportions of women who had ever experienced an abortion: for example, 13\% of women aged 15-44 in Alwar district, Rajasthan, had experienced one or more abortions over the course of their life (Elul et al., 2004) compared to almost one-fourth of those aged 15-39 in six districts of Madhya Pradesh (Malhotra et al., 2003). The case finding approach used in the Maharashtra study among women in three western districts estimated, moreover, an annual induced abortion rate of 15\% (Ganatra et al., 2008). Abortion ratios-the number of abortions per 100 live births-also varied, ranging from about 5 for every 100 live births in Madhya Pradesh and Rajasthan to more than twice that (11-14, depending on the methodology employed) in Maharashtra.

These studies also document women's knowledge of the legality of abortion, awareness and practice of sex-selective abortion, providers from whom women sought their abortion, and the post-abortion complications they experienced. They confirm that while knowledge of the legality of abortion was limited, most women were aware of sex-selective abortion. For example, three-quarters of women in the Rajasthan study knew that foetal sex could be determined and a similar proportion knew someone who had undergone a sex-selective abortion. However, 3\% of women who underwent abortion in the Rajasthan and Madhya Pradesh studies compared to $17 \%$ of those in the Maharashtra study, reported sex-selection as a reason for their abortion.
Variation was also observed in the percentage of women who obtained services from outside the formal sector. For example, $20 \%$ of the women who had sought an abortion in the five years preceding the interview in the Rajasthan study reportedly used a home remedy or the services of an informal provider (Elul et al., 2004) while half of rural women in the Madhya Pradesh study, reported an abortion using "dubious and potentially dangerous means" (Malhotra et al., 2003). In Maharashtra, $45 \%$ of all abortions were carried out by providers who were either not legally recognised as MTP service providers or performed in a place not legally approved for abortion; however, just $2 \%$ and $12 \%$ were conducted by traditional practitioners and those trained in non-allopathic systems of medicine, respectively.

Post-abortion morbidity was reported by large proportions of women: $68 \%$ in the Maharashtra study, 54\% in the Madhya Pradesh study and 26\% in the Rajasthan study.

\section{Settings}

The Consortium for Safe Abortions in India, as mentioned earlier, comprises several major players in the abortion field in the country. Its main goal is to increase poor rural women's access to legal, safe and comprehensive abortion services, including post-abortion family planning, in the public health system. The Consortium has developed a model that works on several fronts: (a) upgrading facilities, that is, training providers to perform abortions and ensuring that necessary equipment and supplies are available and functioning; (b) empowering 
women and communities to access these services and demand quality care; as well as (c) advocating, with evidence, for macro-level changes that enable expansion of the provider base for providing MVA and medical abortion and other changes in policies, laws, rules, regulations and practices to increase access to safe abortion services in the public and private sectors. The model has been closely monitored and will be rigorously evaluated in order to enable evidence based directions for programming.

Aurangabad and Tonk districts were selected purposively as intervention districts because of the previous engagement of Consortium partners in these districts. Nevertheless, these districts were not atypical of Maharashtra and Rajasthan respectively, in terms of socio-demographic characteristics, as shown in Table 1.1. Control districts-Jalna and Bundi-were matched on the basis of literacy and economic activity profiles. As evident from Table 1.1, the socio-demographic characteristics in intervention and control districts are similar.

In Maharashtra, Aurangabad accounted for about $3 \%$ and Jalna $2 \%$ of the state's total population of 96.8 million as of 2001 (Office of the Registrar General and Census Commissioner, 2004). Gender differences are quite stark in both districts-for example, literacy rates ranged from 49-60\% among females to $79-85 \%$ among males. Both districts were similar, moreover, in terms of work participation levels, modern contraceptive use,

\section{Table 1.1}

Socio-demographic characteristics of study districts and states, 2000s

\begin{tabular}{|c|c|c|c|c|c|c|}
\hline & \multicolumn{3}{|c|}{ Maharashtra } & \multicolumn{3}{|c|}{ Rajasthan } \\
\hline & Aurangabad & Jalna & Maharashtra & Tonk & Bundi & Rajasthan \\
\hline Total population ${ }^{\mathrm{a}}$ & $2,897,013$ & $1,612,980$ & $96,878,627$ & $1,211,671$ & 962,620 & $56,507,188$ \\
\hline Sex ratio $(M / F)^{a}$ & 924 & 951 & 922 & 934 & 907 & 921 \\
\hline Juvenile sex ratio $(M / F)^{a}$ & 890 & 903 & 913 & 927 & 912 & 909 \\
\hline Male literacy $^{1 \text { a }}(\%)$ & 84.9 & 79.1 & 86.0 & 70.5 & 71.7 & 75.7 \\
\hline Female literacy ${ }^{1 \text { a }}(\%)$ & 60.1 & 49.0 & 67.0 & 32.2 & 37.8 & 43.9 \\
\hline Male work participation ${ }^{1 \text { a }}(\%)$ & 59.1 & 60.2 & 62.1 & 60.5 & 65.7 & 61.6 \\
\hline Female work participation ${ }^{1 \text { a }}(\%)$ & 37.0 & 45.6 & 35.8 & 46.9 & 49.5 & 41.2 \\
\hline $\operatorname{Urban}^{\mathrm{a}}(\%)$ & 38.8 & 19.1 & 42.4 & 20.9 & 18.7 & 23.4 \\
\hline Modern contraceptive use ${ }^{\mathrm{b}}(\%)$ & 55.5 & 54.3 & 60.8 & 44.3 & 38.7 & 42.3 \\
\hline $\begin{array}{l}\text { Unmet need for } \\
\text { contraception }^{\mathrm{b}}(\%)\end{array}$ & 14.4 & 12.8 & 12.6 & 14.6 & 24.1 & 21.8 \\
\hline $\begin{array}{l}\text { Mothers who had at least three } \\
\text { antenatal check-ups for the } \\
\text { last birth }{ }^{\mathrm{b}}(\%)\end{array}$ & 28.0 & 13.2 & 23.0 & 3.1 & 6.1 & 5.0 \\
\hline Institutional deliveries ${ }^{\mathrm{b}}(\%)$ & 54.8 & 51.3 & 57.9 & 25.8 & 36.2 & 31.4 \\
\hline $\begin{array}{l}\text { Skilled attendance at } \\
\text { delivery }{ }^{\mathrm{b}}(\%)\end{array}$ & 60.5 & 56.0 & 62.6 & 41.6 & 48.2 & 44.4 \\
\hline
\end{tabular}

Note: ${ }^{1}$ Ages 7 and above.

Sources: ${ }^{a}$ Office of the Registrar General and Census Commissioner (2004); ${ }^{b}$ International Institute for Population Sciences (2006). 
institutional deliveries and deliveries by skilled birth attendants.

The two districts of Rajasthan showed considerably lower development indicators than those of Maharashtra, notably in terms of literacy, pregnancy-related care and contraceptive practice. Of the state's population of 56.5 million, Bundi and Tonk accounted for $2 \%$ each. As in the selected districts of Maharashtra, gender differences in literacy are significant-32-38\% among females compared to $71-72 \%$ among males. Moreover, both districts were similar in terms of contraception and pregnancy-related care.

\section{Study design}

In order to both inform the design of the model and provide benchmark indicators at facility, provider and client levels as well as at the community level, quasi-experimental research was undertaken in the two intervention districts-Aurangabad in Maharashtra and Tonk in Rajasthan-and the two matched control districts (Jalna and Bundi respectively). Baseline research comprised three components. First, a facility level survey (including a facility-level checklist) was fielded in all PHCs and Rural Hospitals (RHs, the term used for CHCs in Maharashtra) in the selected districts of Maharashtra, and $\mathrm{CHCs}$ in the selected districts of Rajasthan that interviewed medical officers in charge of each facility (and other medical officers or, in their absence, as in the case of some PHCs, the senior-most nursing staff member). The questionnaire included an inventory of equipment and supplies as well as questions relating to staffing patterns, infrastructure and facilities available; services provided and so on as well as provider-level factors such as experience and qualifications of doctors including those in the area of abortion, and knowledge and understanding of providers with regard to abortion. Second, a client survey was fielded that assessed, through exit interviews, women's perceptions of quality of care and services provided by the facility (not necessarily relating to abortion). These two facility-based components of the study were conducted during July-November 2006 and their findings are reported elsewhere (Kalyanwala et al., 2010).

A third component, a community-based survey was conducted during August 2007-March 2008 in both states to assess the level of demand for abortion among rural women, abortion experiences and community-level needs. Study instruments drew on those used in previous studies, notably those by Elul et al. (2004) and Malhotra et al. (2003) discussed above. Findings from this phase of the study are covered in this report.

\section{Sampling}

A cross-sectional community-based survey of currently married women aged $15-39(\mathrm{n}=4,600)$ was carried out in selected sites in both states.

The survey was conducted in a sample of villages served by the facilities selected for intervention in Aurangabad and Tonk, and a similarly situated set of villages in Jalna and Bundi. During the facility-based phase, we covered all of the 106 facilities in the two districts of Maharashtra (50 PHCs and 9 RHs in Aurangabad, and 37 PHCs and 10 RHs in Jalna) and all of the 80 facilities in the two districts of Rajasthan (45 PHCs and 7 CHCs 
in Tonk, and 24 PHCs and 4 CHCs in Bundi). A composite index was constructed, that summarized the readiness of facilities to house the intervention. This index was based on the general infrastructure, the infrastructure required for service provision, the availability of essential equipment, the number of doctors, the availability of a female doctor, the number of MTP trained doctors or obstetriciansgynaecologists, and the constellation of reproductive health services provided (for more details, see Kalyanwala et al., 2010). All PHCs scoring in the upper ranges of the index in each state (18 and above in Maharashtra and 13 and above in Rajasthan) were selected for intervention, along with all CHCs and RHs. Our survey was, therefore, conducted in the areas served by each of these facilities as well as in areas served by a corresponding set of facilities in each of the control sites. A total of $23 \mathrm{PHC}$ areas were thus selected in Aurangabad, 18 in Jalna, 25 in Tonk and 24 in Bundi.

In order to determine the sample size, our outcome indicator was the percentage of women correctly aware of the legality of abortion under certain specific conditions. We assumed, on the basis of available literature and discussion at Consortium meetings, that this percentage should be approximately $10 \%$ and use the following formula for estimating minimum sample size:

$$
\mathrm{q} / \mathrm{np}=\mathrm{cv}^{2}
$$

The co-efficient of variation (cv) was fixed at 0.1 or $10 \%$ (equivalent to fixing absolute error at $20 \%$ of true value and estimating with $95 \%$ confidence) and $\mathrm{p}$ as $0.10, \mathrm{q}=0.90$; these were used to obtain the required sample size (n) of 900 .
We proposed, therefore, to aim for a sample size of 1,000 married women aged 15-39 in the control and intervention sites, that is, a total survey of 4,000 women in the two states. We further determined that no more than 25 women would be selected from each village of the Primary Sampling Unit (PSU); hence, that a total of 40 PSUs or villages would be visited in each district.

The 2001 Census list of villages served as the sampling frame for the selection of villages. At the first level of stratification, each district was stratified into blocks and the number of villages to be selected from each block was determined according to the share of the population of that block to that of the district. In each block, villages were further stratified by size and the percentage of the populations belonging to scheduled castes or scheduled tribes. The last level of stratification consisted of an order of villages within each stratum by level of female literacy, ordered alternatively in increasing and decreasing levels of female literacy (obtained from the 2001 Census Village Directory). Villages were then selected systematically from the stratified list described above, with selection probability proportional to size (PPS).

A complete mapping and household listing operation was carried out in each selected PSU or in selected segments or linked villages as appropriate (large villages were segmented into approximately 150 households and two segments were selected randomly). The list of households provided the necessary frame for selecting households at the second stage. In each PSU, the households to be interviewed were selected by systematic sampling. 
The value of the interval (between one selected household and the next) was determined in advance to ensure a self-weighting design at the district level. All eligible women in the selected household were selected for interview and no replacement was permitted.

\section{Data collection and analysis}

All data collection took place between August 2007 and March 2008. Two structured instruments-a household questionnaire and a woman's questionnaire-were used to collect data in a face-toface interview.

The household questionnaire was designed to gather demographic information about all permanent household members, as well as information on household socio-economic status. It was also used to identify currently married women aged 15-39 who would be eligible for the individual interview.

The woman's questionnaire included background information of female respondents as well as their reproductive and abortion experiences, knowledge of abortion legislation and available methods of abortion, attitudes towards abortion, and key issues in selecting an abortion provider or facility. Abortion experiences covered the method of abortion experienced (surgical, medical), complications experienced and quality of care received.

Information on women's reproductive experiences was obtained using (a) a detailed birth history, and (b) a detailed history of reproductive events experienced in the five years prior to the interview by way of a calendar that provided monthwise data on women's pregnancy status, contraceptive practice, abortions, stillbirths and miscarriages.

Study instruments were prepared in English and translated into Marathi and Hindi. They were pre-tested in both settings and modified accordingly.

A team of 23 female investigators in Maharashtra and 15 in Rajasthan were recruited for data collection. The investigators underwent an intensive one-week training which focused on interviewing methods and the details of the questionnaire, it also covered basic reproductive health concepts, and familiarisation with the various techniques of and terminologies used for abortion.

This report presents the findings of the combined data drawn from women in the two selected districts of these states. Data were entered in CSPro and analysed using SPSS-11.0. All means, medians and percentages indicated in the tables have been weighted using normalised weights for the total population. However, in order to show the total number of women interviewed, unweighted numbers of respondents (Ns) are provided in each table. Because numbers are unweighted and percentages are weighted, we caution readers against deriving numbers based on the percentages provided in the tables.

Corresponding (unweighted) district-wise information is available in Appendix Tables 1 to 4 .

\section{Sample coverage}

Table 1.2 provides the response rates for household and individual interviews. A total of 5,807 


\section{Table 1.2}

Coverage of the study

\begin{tabular}{l|c|c} 
& Aurangabad and Jalna, Maharashtra & Bundi and Tonk, Rajasthan \\
\hline Number of villages selected & 80 & 80 \\
Number of households selected & 3,379 & 2,428 \\
Household response rate & 96.3 & 96.1 \\
Number of currently married women & & 2,049 \\
$\quad$ aged 15-39 identified & 2,956 & 95.3
\end{tabular}

households, yielding a total of 5,005 eligible women were approached to participate in the study. The household response rate was $96 \%$ for both states; the response rate for eligible women in the two states was $90-95 \%$.

\section{Structure of this report}

The report has five main sections. Chapter 2 describes the socio-demographic characteristics of respondents in each state. Chapter 3 addresses women's awareness of and attitudes to abortion; it also covers women's exposure to abortion-related messages and the source of these messages.

Chapter 4 describes the prevalence of abortion, and Chapter 5 documents the experiences of women reporting abortions, including decision-making, quality of care and counselling, post-abortion complications and post-abortion contraception. Chapter 6 summarises the findings of this study and offers programmatic recommendations to ensure greater access to safe abortion among rural women in these states. 


\section{CHAPTER 2}

\section{Social and demographic characteristics of households and respondents}

In this chapter, we present the socio-demographic profiles of study households and individual respondents.

\section{Characteristics of households}

As evident in Table 2.1, the majority of structures in which the respondents resided were self-owned; the majority of respondents also owned agricultural land. More respondents in Bundi and Tonk, Rajasthan, than in Aurangabad and Jalna, Maharashtra, owned the structure in which they resided $(98 \%$ versus $90 \%)$ and owned agricultural land (77\% versus $69 \%)$. The average household size was about 5 in each setting. Household amenities were, however, considerably more likely to be reported by respondents in the Maharashtra settings than those in the Rajasthan settings. For example, respondents in Aurangabad and Jalna were more likely than their counterparts in Bundi and Tonk to live in pucca structures (31\% versus $27 \%$ ), have their own flush toilet $(12 \%$ versus $8 \%)$, have electricity $(71 \%$ versus $49 \%$ ), and their own piped water/hand pump/ covered well (27\% versus $14 \%$ ).

Household economic status was measured using an index composed of household asset data on ownership of selected durable goods as well as data on access to amenities, and ownership of agricultural land; it was adapted from the household standard of living index used in the Youth in India:
Situation and Needs study (International Institute for Population Sciences and Population Council, 2008). The index was constructed for the entire sample of women from both states, using the following items, with scores assigned as follows: type of household (2 for pucca, 1 for semi-pucca, 0 for kachcha); toilet facility ( 4 for own flush toilet, 2 for public or shared flush toilet, 1 for shared or pit toilet, 0 for no facility); source of lighting ( 3 for electricity, 0 for any other source of lighting); fuel for cooking (2 for electricity, liquid petroleum gas, or biogas, 1 for coal/charcoal/kerosene/wood/crop residue/ dung cakes, 0 for other fuels); source of drinking water ( 4 for own piped water, hand pump, covered well; 3 for own open well; 2 for public or shared piped water, hand pump, covered well; 1 for public or shared open well, 0 for other water sources); ownership of agricultural land (4 for more than 10 acres, 3 for $5.1-10.0$ acres, 2 for 2.6-5.0 acres, 1 for less than 2.6 acres or acreage not known, 0 for no agricultural land); and ownership of different durable goods ( 4 for car; 3 each for motor cycle or scooter, refrigerator, computer/laptop, land line/ mobile and colour television; 2 each for bicycle, electric fan, radio/transistor, sewing machine, black and white television, water pump and animal drawn cart; 1 for a watch/clock, and 0 for each item that the household did not possess). ${ }^{1}$ Index scores, so constructed, ranged from 0 to 53 .

${ }^{I}$ One variable included in the Youth in India: Situation and Needs study definition could not be included here, namely, ownership of irrigated land. 


\section{Table 2.1}

Characteristics of households

\begin{tabular}{|c|c|c|}
\hline & $\begin{array}{l}\text { Aurangabad and Jalna, } \\
\text { Maharashtra }\end{array}$ & $\begin{array}{l}\text { Bundi and Tonk, } \\
\text { Rajasthan }\end{array}$ \\
\hline \multicolumn{3}{|l|}{ Ownership of residence } \\
\hline Own home (\%) & 90.0 & 97.7 \\
\hline \multicolumn{3}{|l|}{ Household size } \\
\hline Mean number of usual household members & 5.2 & 5.4 \\
\hline \multicolumn{3}{|l|}{ Type of house } \\
\hline Pucca structure (\%) & 30.7 & 26.6 \\
\hline \multicolumn{3}{|l|}{ Ownership of agricultural land } \\
\hline Own agricultural land (\%) & 68.6 & 77.2 \\
\hline \multicolumn{3}{|l|}{ Household amenities } \\
\hline Toilet facility: own flush toilet (\%) & 11.7 & 7.5 \\
\hline Source of lighting: Electricity (\%) & 70.7 & 49.2 \\
\hline $\begin{array}{l}\text { Source of drinking water: Own piped water/hand pump/covered } \\
\text { well }(\%)\end{array}$ & 27.0 & 14.1 \\
\hline \multicolumn{3}{|l|}{ Economic status } \\
\hline Low & 34.3 & 47.9 \\
\hline Medium & 44.6 & 34.0 \\
\hline High & 20.8 & 18.0 \\
\hline Mean (0-53) & 15.0 & 13.4 \\
\hline Number of households & 3,253 & 2,334 \\
\hline
\end{tabular}

Note: All Ns are unweighted.

Households were then ranked according to the index score and divided into three groups, representing low (bottom 40\%), medium (middle $40 \%$ ) and high (top 20\%) economic status. Findings show that mean scores on the household economic status index were slightly lower in Bundi and Tonk, Rajasthan, than in Aurangabad and Jalna, Maharashtra (13 versus 15). In total, about one-third of households in the two districts of Maharashtra $(34 \%)$ and almost half (48\%) of those in the two districts of Rajasthan were classified as having low economic status.

\section{Characteristics of respondents}

Table 2.2 presents the socio-economic characteristics of respondents. On average, respondents were 26-27 years old, and about three in five respondents in the surveyed settings of each state had worked in the 12 months preceding the interview. In contrast, educational attainment levels varied widely by state. 


\section{Table 2.2}

Socio-demographic profile of respondents

\begin{tabular}{|c|c|c|}
\hline Socio-demographic factors & $\begin{array}{c}\text { Aurangabad and Jalna, } \\
\text { Maharashtra }\end{array}$ & $\begin{array}{c}\text { Bundi and Tonk, } \\
\text { Rajasthan }\end{array}$ \\
\hline Mean age & 25.7 & 27.4 \\
\hline \multicolumn{3}{|l|}{ Educational attainment } \\
\hline Never attended school (\%) & 37.9 & 74.8 \\
\hline Completed Class 10 or higher (\%) & 16.4 & 4.9 \\
\hline Mean years of education completed & 4.5 & 1.8 \\
\hline \multicolumn{3}{|l|}{ Working status } \\
\hline Worked in the last year (\%) & 57.4 & 59.2 \\
\hline \multicolumn{3}{|l|}{ Household economic status } \\
\hline Low & 25.7 & 39.5 \\
\hline Medium & 46.7 & 35.7 \\
\hline High & 27.2 & 24.7 \\
\hline Mean score $(0-53)$ & 17.0 & 15.0 \\
\hline \multicolumn{3}{|l|}{ Total number of children ever born (\%) } \\
\hline 0 & 14.8 & 15.8 \\
\hline 1 & 16.5 & 16.3 \\
\hline 2 & 25.2 & 21.4 \\
\hline $3+$ & 43.5 & 46.6 \\
\hline Mean & 2.3 & 2.5 \\
\hline \multicolumn{3}{|l|}{ Total number of surviving children } \\
\hline 0 & 15.6 & 16.6 \\
\hline 1 & 17.8 & 17.8 \\
\hline 2 & 28.0 & 24.1 \\
\hline $3+$ & 38.6 & 41.4 \\
\hline Mean & 2.1 & 2.2 \\
\hline \multicolumn{3}{|l|}{ Total number of surviving sons } \\
\hline 0 & 28.7 & 30.0 \\
\hline 1 & 36.7 & 34.0 \\
\hline 2 & 29.0 & 29.5 \\
\hline $3+$ & 5.6 & 6.4 \\
\hline Mean & 1.1 & 1.1 \\
\hline \multicolumn{3}{|l|}{ Total number of surviving daughters } \\
\hline 0 & 38.1 & 39.2 \\
\hline 1 & 36.1 & 32.8 \\
\hline 2 & 17.5 & 16.9 \\
\hline $3+$ & 8.4 & 11.1 \\
\hline Mean & 1.0 & 1.0 \\
\hline Women experienced at least one child death & 14.8 & 22.3 \\
\hline Number of women & 2,647 & 1,953 \\
\hline
\end{tabular}

Note: All Ns are unweighted. 
In the two districts of Maharashtra, for example, almost two-fifths $(38 \%)$ of all women had never been to school and $16 \%$ had completed high school; in comparison, three-quarters of all respondents in the two districts of Rajasthan had never been to school, and just 5\% had completed high school. Household economic status also varied-two-fifths of respondents from the Rajasthan settings, compared to one-quarter $(26 \%)$ of those from the Maharashtra settings came from households with low economic status.

Fertility levels were similar among women from the surveyed settings of both states-2.3-2.5 live births and 2.1-2.2 surviving children, respectively, with slightly more sons than daughters. However, a considerably larger proportion of women from the two districts of Rajasthan than from the two districts of Maharashtra had experienced one or more child deaths (22\% versus $15 \%)$.
Awareness and practice of contraception

As seen in Table 2.3, awareness of both terminal and non-terminal methods of contraception were almost universal in both states. Large proportions of women had, moreover, practised contraception at some point in their life: $66 \%$ in Aurangabad and Jalna, Maharashtra, and 56\% in Bundi and Tonk, Rajasthan. Indeed, $29 \%$ and $20 \%$ of women from these districts of Maharashtra and Rajasthan, respectively, had practised a modern non-terminal method at some point in their life.

At the time of interview, $56 \%$ of women from the two districts of Maharashtra compared to slightly fewer $(50 \%)$ from the two districts of Rajasthan were practising contraception. The method mix was not strikingly different between the two states. About three-quarters of all women reporting contraception had opted for sterilisation, and the leading non-terminal method used in both states was the condom. 


\section{Table 2.3}

Percentage of women who reported awareness of various contraceptive methods and practice of family planning

\begin{tabular}{|c|c|c|}
\hline & $\begin{array}{c}\text { Aurangabad and Jalna, } \\
\text { Maharashtra }\end{array}$ & $\begin{array}{c}\text { Bundi and Tonk, } \\
\text { Rajasthan }\end{array}$ \\
\hline \multicolumn{3}{|l|}{ Awareness of: } \\
\hline At least one terminal method & 97.0 & 99.0 \\
\hline At least one modern non-terminal method & 89.6 & 96.5 \\
\hline Ever use of: & 66.0 & 55.7 \\
\hline Any method & 29.3 & 19.5 \\
\hline \multicolumn{3}{|l|}{ Any modern non-terminal method } \\
\hline \multicolumn{3}{|l|}{ Current use of: } \\
\hline Any method & 56.4 & 50.2 \\
\hline Terminal methods & 41.9 & 37.4 \\
\hline Female sterilization & 41.7 & 36.7 \\
\hline Male sterilization & 0.2 & 0.7 \\
\hline Modern non-terminal methods & 11.6 & 7.3 \\
\hline $\mathrm{IUD} / \mathrm{Cu}-\mathrm{T}$ & 1.4 & 0.5 \\
\hline Pill & 2.6 & 1.9 \\
\hline Condom & 7.6 & 4.8 \\
\hline Injectables & 0.0 & 0.1 \\
\hline Traditional methods ${ }^{1}$ & 2.9 & 5.0 \\
\hline Rhythm/safe period & 1.7 & 1.0 \\
\hline Withdrawal & 1.3 & 4.0 \\
\hline Total & 100.0 & 100.0 \\
\hline Number of women & 2,647 & 1,953 \\
\hline
\end{tabular}

Note: All Ns are unweighted.

${ }^{1} 0.5 \%$ of respondents from Rajasthan reported the use of folk methods, including jadi buti and desi dawai. 


\section{Awareness of and perceptions about abortion}

This chapter presents information on women's awareness of methods of abortion (surgical and medical), the location of facilities providing abortion and the legality of abortion, and perceptions about where women in the community accessed these services. It also provides information on women's attitudes about abortion, the conditions under which it is accessible to women and key factors to consider while selecting an abortion provider. Besides, information about women's familiarity with sex determination and sex-selective abortion is also provided. Finally, the chapter sheds light on women's sources of information about abortion.

\section{Awareness of abortion methods}

As evident from Table 3.1, the majority, $73 \%$ and $77 \%$ of women in the two districts of Rajasthan and Maharashtra, respectively, had heard about surgical abortion. Fewer-and now more women from the districts of Rajasthan than the districts of Maharashtra (64\% and 50\%, respectively)—had heard about abortion through the use of oral medication. Since we did not probe the exact nature of the oral medication, and since there are a variety of Ayurvedic and other preparations available that are believed to induce abortion, it is very unlikely that all of these women were reporting awareness of the mifepristone-misoprostol combination.

Altogether, some four-fifths (82-83\%) had heard of any method of abortion.

\section{Facilities providing abortion services}

Findings presented elsewhere have documented that not a single PHC in Bundi and Tonk districts of Rajasthan and just 1 of 87 in Aurangabad and Jalna districts of Maharashtra were providing abortion services at the time of the survey, and further, that even at the $\mathrm{CHC} / \mathrm{RH}$ level, abortion services were provided at just 5 of 19 and 7 of 11 facilities in the surveyed settings of Maharashtra

Table 3.1

Awareness of abortion methods: Percentage of women who reported awareness of methods of safe abortion

\begin{tabular}{|l|c|c|}
\hline Women reporting awareness of any method of abortion & $\begin{array}{c}\text { Aurangabad and Jalna, } \\
\text { Maharashtra }\end{array}$ & $\begin{array}{c}\text { Bundi and Tonk, } \\
\text { Rajasthan }\end{array}$ \\
\hline $\begin{array}{l}\text { Women reporting awareness of specific methods }{ }^{\mathbf{1}} \\
\text { Surgical methods }\end{array}$ & 83.2 & 81.5 \\
$\quad$ Medical Abortion & 76.7 & 72.7 \\
Number of women & 49.8 & 63.5 \\
\hline
\end{tabular}

Note: All Ns are unweighted.

${ }^{1}$ Multiple responses possible. 
and Rajasthan, respectively (Kalyanwala et al., 2010). Given these findings, it is notable that $20 \%$ and $56 \%$ of women in Aurangabad and Jalna, and in Bundi and Tonk, respectively, believed that abortion services were available at $\mathrm{PHC}$ or $\mathrm{CHC} /$ $\mathrm{RH}$ levels (Table 3.2). Also notable is that just 55\% of women in the Rajasthan sites and $29 \%$ of those in the Maharashtra sites were aware that abortion services were available at the District Hospital. In total, awareness of abortion services at public sector facilities varied widely: from just two in five (38\%) in the two districts of Maharashtra to four in five $(80 \%)$ in the two districts of Rajasthan. The reverse was true about awareness of private sector abortion facilities. While $62 \%$ of women in the two districts of Maharashtra were aware of abortion facilities or providers in the private sector, just $30 \%$ of those in the two districts of Rajasthan were so aware. In total, just $73 \%$ of women in the two districts of Maharashtra and somewhat more (81\%) in the two districts of Rajasthan were aware that abortion services could be accessed from a public or private sector facility.

A considerable proportion of women reported that abortion services were provided by such providers as nurses and chemists, that is, those not legally permitted to prescribe or conduct abortions under the MTP Act. Indeed, one-quarter (24\%) of women from Aurangabad and Jalna, Maharashtra, and half (48\%) of those from Bundi and Tonk, Rajasthan, believed that abortion services were provided by nurses and ANMs $(2 \%$ and $16 \%$, respectively) and chemists (23\% and $41 \%$, respectively).

\section{Table 3.2}

Awareness of facilities providing abortion: Percentage of women who reported awareness of facilities providing abortion

\begin{tabular}{|c|c|c|}
\hline & $\begin{array}{l}\text { Aurangabad and Jalna, } \\
\text { Maharashtra }\end{array}$ & $\begin{array}{l}\text { Bundi and Tonk, } \\
\text { Rajasthan }\end{array}$ \\
\hline $\begin{array}{l}\text { Awareness of public or private sector facilities/providers of } \\
\text { abortion services }{ }^{1}\end{array}$ & 72.6 & 81.4 \\
\hline Any public sector facility & 38.1 & 79.9 \\
\hline District Hospital & 28.8 & 54.8 \\
\hline CHC/Rural Hospital or PHC & 19.7 & 56.1 \\
\hline Private sector facility/doctor & 61.9 & 30.0 \\
\hline Awareness of other providers of abortion services ${ }^{1}$ & 24.2 & 48.3 \\
\hline ANM/Nurse & 1.7 & 16.2 \\
\hline Chemist & 23.1 & 41.1 \\
\hline Awareness only of likely unsafe sources of abortion & 3.5 & 3.7 \\
\hline Number of women & 2,647 & 1,953 \\
\hline
\end{tabular}

Note: All Ns are unweighted.

${ }^{1}$ Multiple responses possible. 
Findings also suggest that most women who reported that nurses, ANMs and chemists provided abortion services were also aware of public or private sector physicians who provided these services. Indeed, just $4 \%$ of women in both sites believed that services could only be procured through a nurse, ANM or chemist.

In short, large proportions of women (19-27\%) were unaware that abortion services are available at public or private sector facilities, and in Aurangabad and Jalna, Maharashtra, many more were unaware that services are available at public sector facilities $(62 \%)$. At the same time, large proportions-indeed half of those from Bundi and Tonk, Rajasthan-reported that abortion services were available from providers currently outside the provisions of the MTP Act.
Women were also asked about facilities from which or providers from whom women in their community were likely to seek abortion services. Findings, reported in Table 3.3, mirror those reported above. The majority of women in the two districts of Maharashtra reported that women would seek abortion services from a private sector physician (62\%), and the majority of those from the two districts of Rajasthan reported that they would do so from a public sector facility, namely a District Hospital, CHC or PHC (96\%). Notably, despite the considerable awareness that nurses, ANMs, chemists and others provided abortion services, few women in both settings reported that women would seek abortion services from such providers-just 7\% and $5 \%$ in the two districts of Maharashtra and Rajasthan, respectively.

\section{Table 3.3}

Perceptions about community access to abortion: Percent distribution of women by perceptions about where women in the community access abortion

\begin{tabular}{|c|c|c|}
\hline & $\begin{array}{c}\text { Aurangabad and Jalna, } \\
\text { Maharashtra }\end{array}$ & $\begin{array}{c}\text { Bundi and Tonk, } \\
\text { Rajasthan }\end{array}$ \\
\hline Any public sector facility ${ }^{1}$ & 39.0 & 96.1 \\
\hline District Hospital & 31.0 & 71.3 \\
\hline CHC/Rural Hospital or PHC & 16.0 & 56.0 \\
\hline Private sector facility/doctor ${ }^{1}$ & 62.1 & 19.2 \\
\hline Other providers ${ }^{1}$ & 6.8 & 4.8 \\
\hline ANM/Nurse & 3.6 & 3.9 \\
\hline Chemist & 1.7 & 0.5 \\
\hline Dai/TBA/herbalist/other traditional practitioner & 1.7 & 0.1 \\
\hline Others & 0.7 & 0.5 \\
\hline Don't know & 18.5 & 1.8 \\
\hline Number of women & 2,647 & 1,953 \\
\hline
\end{tabular}

Note: All Ns are unweighted.

${ }^{1}$ Multiple responses possible. 


\section{Legal issues related to abortion}

Questions regarding the legality of abortion probed whether women were aware that abortion is legal in a host of situations, as described in Table

3.4. Findings highlight that $77 \%$ and $73 \%$ of women in the Maharashtra and Rajasthan settings, respectively, were aware that abortion is legal in at least one situation. However, misconceptions abound with regard to the legality of abortion in various situations. For example, almost half of all women in both states believed that an unmarried woman and a woman, whose pregnancy results from contraceptive failure cannot legally access abortion; $40 \%$ of women from Aurangabad and Jalna, Maharashtra, and 47\% of those from Bundi and Tonk, Rajasthan, believed that abortion is illegal in case of rape. As many as one-third (30-34\%) of the women in Aurangabad and Jalna, Maharashtra and two-fifths of those from Bundi and Tonk, Rajasthan (40\% each) believed that abortion is illegal even if the woman's health is endangered by the pregnancy or if there is a chance of serious defects in the baby. In contrast, few women from both settings held misperceptions

Table 3.4

Awareness of legal issues related to abortion: Percentage of women by misperceptions held about the legality of abortion and awareness of at least one situation in which abortion is legal

\begin{tabular}{|c|c|c|}
\hline & $\begin{array}{l}\text { Aurangabad and Jalna, } \\
\text { Maharashtra }\end{array}$ & $\begin{array}{l}\text { Bundi and Tonk, } \\
\text { Rajasthan }\end{array}$ \\
\hline \multicolumn{3}{|l|}{ Women correctly aware of: } \\
\hline At least one condition under which abortion is legal & 76.7 & 73.3 \\
\hline \multicolumn{3}{|l|}{ Misperceptions held: \% who reported that it is illegal: } \\
\hline For an unmarried woman to access abortion & 48.6 & 47.2 \\
\hline $\begin{array}{l}\text { For a woman whose pregnancy results from contraceptive failure } \\
\text { ("accidentally") to access abortion }\end{array}$ & 49.9 & 45.6 \\
\hline $\begin{array}{l}\text { For a woman whose pregnancy has resulted from rape to legally } \\
\text { access abortion }\end{array}$ & 40.4 & 47.2 \\
\hline $\begin{array}{l}\text { For a woman whose health is endangered by the pregnancy to access } \\
\text { abortion }\end{array}$ & 29.9 & 39.8 \\
\hline $\begin{array}{l}\text { If there is a strong chance of foetal malformation, for a woman to } \\
\text { access abortion }\end{array}$ & 34.3 & 39.7 \\
\hline For a woman who is more than 20 weeks pregnant to access abortion & 10.9 & 3.9 \\
\hline \multicolumn{3}{|l|}{ Awareness about consent procedures } \\
\hline $\begin{array}{l}\text { Misperceiving that a woman undergoing abortion needs her husband's } \\
\text { consent }\end{array}$ & 88.1 & 96.9 \\
\hline $\begin{array}{l}\text { Aware that a woman undergoing abortion does not require husband's } \\
\text { consent }\end{array}$ & 5.1 & 1.9 \\
\hline Number of women & 2,647 & 1,953 \\
\hline
\end{tabular}

Note: All Ns are unweighted. 
about the fact that it is illegal for a woman who is more than 20 weeks pregnant to undergo abortion $(4-11 \%)$.

Misinformation about other aspects of the MTP Act was, however, pervasive. Awareness that an adult woman is legally entitled to undergo abortion without the consent of her husband or guardian was very limited. Indeed, as many as $88 \%$ of women from the two districts of Maharashtra and $97 \%$ of those from the two districts of Rajasthan misperceived that it was mandatory for women undergoing abortion to obtain their husband's consent, and only $2-5 \%$ of women from the surveyed settings of the two states were correctly informed about this right of women.

\section{Attitudes about the conditions under which abortion should be permitted}

As indicated in Table 3.5, large proportions of women in both states endorsed abortion in a wide variety of circumstances. Women in Aurangabad and Jalna, Maharashtra, were, moreover, more likely than their counterparts in Bundi and Tonk, Rajasthan, to approve of abortion in almost every situation posed. For example, an overwhelming majority of women from these states approved of abortion for an unmarried woman $(89 \%$ versus $84 \%$ ), if the pregnancy results from rape ( $86 \%$ versus $78 \%$ ), if the woman's health is endangered by the pregnancy ( $92 \%$ versus $78 \%$ ), or if there is a chance of foetal malformation ( $85 \%$ versus $77 \%)$. On the other

\section{Table 3.5}

Abortion related attitudes: Percentage of women by attitudes about the acceptability of abortion in various situations

\begin{tabular}{|c|c|c|}
\hline & $\begin{array}{c}\text { Aurangabad and Jalna, } \\
\text { Maharashtra }\end{array}$ & $\begin{array}{c}\text { Bundi and Tonk, } \\
\text { Rajasthan }\end{array}$ \\
\hline \multicolumn{3}{|l|}{ Agree that a woman can access abortion if: } \\
\hline The woman's health is endangered by the pregnancy & 91.7 & 78.1 \\
\hline The woman is unmarried & 88.9 & 84.3 \\
\hline The pregnancy is a result of rape & 85.9 & 78.0 \\
\hline There is a strong chance of serious defect in the baby & 84.5 & 77.0 \\
\hline The woman does not want another child & 78.9 & 69.5 \\
\hline The woman cannot afford the child & 77.9 & 69.8 \\
\hline The pregnancy is an accident (result of a contraceptive failure) & 63.8 & 56.2 \\
\hline The foetus is female & 48.4 & 12.9 \\
\hline The foetus is male & 10.5 & 4.4 \\
\hline The woman is more than 20 weeks pregnant & 16.4 & 3.7 \\
\hline Number of women & 2,647 & 1,953 \\
\hline
\end{tabular}

Note: All Ns are unweighted. 
hand, respondents were less supportive of abortion if a woman does not want or cannot afford another child $(78-79 \%$ versus $70 \%)$, or if the pregnancy results from contraceptive failure (64\% versus 56\%). Few supported abortion for women who were more than 20 weeks pregnant (4-16\%). Finally, considerably more women from the two districts of Maharashtra (48\%) than from the two districts of Rajasthan (13\%) favoured abortion if the foetus is female; in contrast, few in both states approved of abortion if the foetus is male (4-11\%).

\section{Sources of information about abortion}

All respondents were asked whether they had received any information about abortion in the last year, and more specifically, the sources of such information. Findings, presented in Table 3.6, highlight that neither the media nor the health system were major sources of information on abortion-indeed, just $6-8 \%$ of women from the settings in both states had obtained information from the media (largely TV and radio, not shown in tabular form), and just $10-12 \%$ had obtained their information from health care providers. The leading sources of information in the settings of both states were, in contrast, family members and friends, highlighting the critical role of interpersonal communication in transmitting information about this sensitive topic. For example, $4-5 \%$ of women reported their husband as their main source of information while $9-11 \%$ reported other family members as their main source (not shown in tabular form). The leading sources of information in both settings were neighbours and friends, reported by $16-18 \%$ of women in both states (not shown in tabular form).

\section{Women's own preferences in selecting an abortion provider and facility}

In order to increase women's access to safe abortion

Table 3.6

Sources of information: Percentage of women who obtained information on abortion from various sources

\begin{tabular}{|l|c|c|} 
& $\begin{array}{c}\text { Aurangabad and Jalna, } \\
\text { Maharashtra }\end{array}$ & $\begin{array}{c}\text { Bundi and Tonk, } \\
\text { Rajasthan }\end{array}$ \\
\hline Did not receive any information & $\mathbf{6 3 . 4}$ & $\mathbf{6 7 . 7}$ \\
\hline $\begin{array}{l}\text { Received information from: } \\
\text { Media }\end{array}$ & 5.8 & 7.6 \\
$\quad$ Health care providers ${ }^{2}$ & 10.1 & 12.0 \\
Family members and friends & 29.2 & 23.6 \\
At least any one of the above sources & 36.6 & $\mathbf{3 2 . 3}$ \\
Number of women & $\mathbf{2 , 6 4 7}$ & $\mathbf{1 , 9 5 3}$
\end{tabular}

Note: All Ns are unweighted.

${ }^{1} 0.1-0.3 \%$ did not specify the source of information; ${ }^{2}$ Includes $0.5 \%$ of women in Maharashtra who reported that a chemist provided information to them. 
and improve the quality of care at available facilities, it is important to understand the factors that may influence the selection of an abortion provider and facility. Respondents were asked whether they would seek abortion from a range of male and female providers including those trained in different types of medicine and nurses, dais and chemists. Findings, reported in Table 3.7 suggest that women would overwhelmingly select a female doctor trained in allopathic medicine: indeed, as many as $84 \%$ of women in the two districts of Maharashtra and 93\% of those in the two districts of Rajasthan would opt for a female doctor. Ranking second in both states were nurses, reported by $11 \%$ and $26 \%$ of women from the two districts of Maharashtra and Rajasthan, respectively. Male doctors trained in allopathic medicine ranked third, preferred by just $4-8 \%$ of women. Notably, ayurveds, dais and chemists were reported by very few women (less than $2 \%$ each).
Respondents were also read a list of facility and provider characteristics and asked to indicate whether they would give importance to each characteristic when choosing an abortion facility or provider. Findings are presented in Table 3.8 and again, reiterate the importance of a female provider. Indeed, the largest proportion of women (66-69\%) reported that a female provider was important in selecting a facility for abortion services. Other important factors in both settings were that the facility is well equipped $(68 \%$ and $51 \%$ in the selected districts of Maharashtra and Rajasthan, respectively), costs are reasonable $(52-55 \%)$, and the facility is easily accessible, that is, close to home $(55 \%$ in the surveyed settings of both states).

In contrast, fewer women placed emphasis on the availability of a certified provider, the reputation of the facility or the extent to which it

\section{Table 3.7}

Perceptions about preferred abortion providers: Percentage of women reporting the provider from whom they would seek abortion in case of an unwanted pregnancy

\begin{tabular}{|c|c|c|}
\hline & $\begin{array}{c}\text { Aurangabad and Jalna, } \\
\text { Maharashtra }\end{array}$ & $\begin{array}{c}\text { Bundi and Tonk, } \\
\text { Rajasthan }\end{array}$ \\
\hline \multicolumn{3}{|l|}{ Preferred abortion provider $^{1}$} \\
\hline Female allopathic doctor & 84.3 & 93.1 \\
\hline Male allopathic doctor & 7.8 & 3.5 \\
\hline Nurse & 10.6 & 26.2 \\
\hline Female ayurved doctor & 1.7 & 0.3 \\
\hline Male ayurved doctor & 0.2 & 0.1 \\
\hline Dai & 1.4 & 0.8 \\
\hline Chemist & 0.9 & 0.6 \\
\hline Can't say & 8.7 & 5.1 \\
\hline Number of women & 2,647 & 1,953 \\
\hline
\end{tabular}

Note: All Ns are unweighted.

${ }^{1}$ Multiple responses possible. 


\section{Table 3.8}

Key factors selecting an abortion facility and provider: Percentage of women by factors perceived to be important in selecting a facility and provider for abortion

\begin{tabular}{l|c|c|}
\hline & $\begin{array}{c}\text { Bundi and Tonk, } \\
\text { Rajasthan }\end{array}$ \\
\hline It is very important that: & 66.0 \\
The clinic has a female provider & 67.5 & 69.0 \\
The facility is well equipped & 55.1 & 51.4 \\
The cost of the abortion is low & 54.7 & 51.8 \\
The facility is close to the woman's home & 48.5 & 54.8 \\
The clinic ensures privacy & 44.6 & 38.6 \\
The provider is well known and has a good reputation & 49.7 & 40.3 \\
The provider is legal & 17.0 & 29.0 \\
The facility or provider does not require the husband's consent & & 17.8 \\
The facility or provider does not make post-abortion contraception a \\
condition for abortion
\end{tabular}

Note: All Ns are unweighted.

ensured privacy. Moreover, state-wise differences were apparent, with more women in the two districts of Maharashtra than in the two districts of Rajasthan reporting that these characteristics were important in selecting an abortion facility: $49 \%$ versus $39 \%$ reported that the facility's ability to ensure privacy would be an important criterion in selecting a facility; $45 \%$ versus $40 \%$ cited the reputation of the provider as a key selection factor, and 50\% versus $29 \%$ cited the importance of a provider who is legally entitled to provide abortion services.

Characteristics least likely to influence the selection of an abortion facility were whether post-abortion contraception is made a condition for abortion and whether or not the facility requires the husband's consent. Indeed, just 15-20\% of women from the surveyed sites of both states reported that these two characteristics would influence their choice of facility.

\section{Sex-determination and sex-selective abortion}

As indicated in Table 3.9, the majority of women knew that foetal sex can be determined and statewise differences were not evident (84-85\%). Respondents were also asked to indicate how common they believed such abortions are in their community and were probed about whether they knew of a facility for sex-determination or knew someone who had undergone a sex-selective abortion. Findings, presented in Table 3.9, suggest that of those familiar with sex-determination, about half believed that it was a somewhat or very common practice in their community (47-51\%). Moreover, 


\section{Table 3.9}

Awareness of sex-selective abortion: Percent distribution of women by awareness of sex-selective abortion and its prevalence in their community

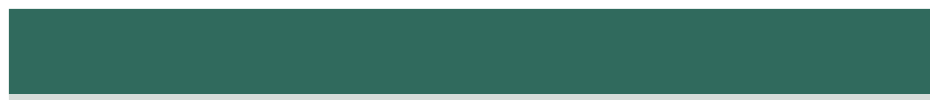

Aware that it is possible to determine the sex of the foetus

Number of women

Of those aware that sex-determination is possible

Belief about prevalence of sex-selective abortion in her community:

Very common

Somewhat common

Not common at all

Can't say

Heard of someone who underwent sex-selective abortion

Knows where sex-determination tests are performed

Number aware that sex-determination is possible

\section{Aurangabad and Jalna, Maharashtra}

85.3

2,647

10.2

41.2

20.1

28.4

39.3

75.7

2,267

\section{Bundi and Tonk,} Rajasthan

84.0

1,953

11.1

35.4

25.1

28.4

49.6

82.4

1,635

Note: All Ns are unweighted.

two-fifths (39\%) of women from the two districts of Maharashtra and half of those from the two districts of Rajasthan knew or had heard of someone who had obtained a sex-selective abortion, and over three-quarters (76-82\%) knew a place where sex-determination tests are performed. 


\section{CHAPTER 4}

\section{Prevalence of induced abortion}

This chapter presents data on the levels of induced abortion. Data are available on the experience of abortion over the course of a woman's lifetime. In addition, using a reproductive life-event calendar, we recorded month-wise information on reproductive events, including abortions experienced over the five years preceding the interview.

\section{Induced abortion levels: lifetime and recent}

A considerable proportion of women in both sites-11-13\%—had undergone an abortion at least once in their lifetime, as evident from Table 4.1. As reports of pregnancies, notably those that had taken place further back in time, can be subject to recall bias, our calendar focused on reproductive events that had occurred in the five years preceding the survey, that is, around 2002-2008. During this fiveyear period, moreover, $7 \%$ of women in Aurangabad and Jalna, Maharashtra, and $4 \%$ of those in Bundi and Tonk, Rajasthan, had deliberately terminated at least one pregnancy.

Abortion ratios, the number of abortions per 100 live births, fell within the range observed in previous community-based studies of women (5 to 11 per 100 live births reported, Elul et al., 2004; Malhotra et al., 2003; Ganatra et al., 2008). The ratios indicate that women in the two districts of Maharashtra and Rajasthan had 7 and 6 abortions, respectively, for every 100 live births experienced over their lifetime. When we include pregnancies from the more recent period, that is, five years prior to the interview, the corresponding ratios are 11 and 8 per 100 live births, respectively. These findings imply that larger proportions of pregnancies occurring in the five years prior to the interview had been terminated compared to those that had taken place up to 15 years prior to the interview.

\section{Table 4.1}

Lifetime and recent abortion: Percentage of women by prevalence of lifetime and recent induced abortion

\begin{tabular}{l|c|c|} 
& $\begin{array}{c}\text { Aurangabad and Jalna, } \\
\text { Maharashtra }\end{array}$ & $\begin{array}{c}\text { Bundi and Tonk, } \\
\text { Rajasthan }\end{array}$ \\
\hline Lifetime & 12.8 & 11.1 \\
$\quad$ Experienced induced abortion (\%) & 6.8 & 5.7 \\
$\quad$ Abortion ratio* & & 4.4 \\
During past five years & 6.8 & 8.2 \\
$\quad$ Experienced induced abortion (\%) & 11.3 & 8.2 \\
Abortion ratio*
\end{tabular}

*Abortions per 100 children ever born (6,112 and 4,814 in Maharashtra and Rajasthan, respectively) and per 100 children ever born in the last five years (1,955 and 1,415, respectively). 


\section{Table 4.2}

Prevalence of lifetime and recent abortions by background characteristics of women

\begin{tabular}{|c|c|c|c|c|}
\hline & \multicolumn{2}{|c|}{ Lifetime } & \multicolumn{2}{|c|}{ During past five years } \\
\hline & $\begin{array}{l}\text { Aurangabad } \\
\text { and Jalna, } \\
\text { Maharashtra }\end{array}$ & $\begin{array}{c}\text { Bundi and Tonk, } \\
\text { Rajasthan }\end{array}$ & $\begin{array}{l}\text { Aurangabad } \\
\text { and Jalna, } \\
\text { Maharashtra }\end{array}$ & $\begin{array}{c}\text { Bundi and Tonk, } \\
\text { Rajasthan }\end{array}$ \\
\hline Women reporting an induced abortion & 12.8 & 11.1 & 6.8 & 4.4 \\
\hline \multicolumn{5}{|l|}{ Current age } \\
\hline $15-24$ & 9.4 & 4.3 & 7.9 & 2.7 \\
\hline $25-29$ & 18.7 & 12.7 & 10.2 & 6.5 \\
\hline $30-39$ & 14.5 & 16.3 & 2.9 & 4.7 \\
\hline \multicolumn{5}{|l|}{ Educational attainment levels } \\
\hline None & 10.3 & 9.4 & 4.5 & 3.6 \\
\hline $1-7$ & 14.1 & 14.2 & 6.8 & 4.1 \\
\hline $8-9$ & 13.6 & 16.9 & 8.8 & 7.7 \\
\hline $10+$ & 15.7 & 20.0 & 10.6 & 11.6 \\
\hline \multicolumn{5}{|l|}{ Household economic status } \\
\hline Low & 7.9 & 7.9 & 4.1 & 3.6 \\
\hline Medium & 12.7 & 10.6 & 7.3 & 3.1 \\
\hline High & 17.5 & 16.8 & 8.6 & 7.2 \\
\hline Number of women & 2,647 & 1,953 & 2,647 & 1,953 \\
\hline
\end{tabular}

Note: All Ns are unweighted.

Table 4.2 provides differentials in the prevalence of abortion (lifetime and during the five years prior to the interview) by women's age, educational attainment level and household standard of living. While older women were clearly more likely to have ever experienced an abortion, recent abortions were more likely to have been experienced by those aged 25-29 than either younger or older women. Differences by education and household economic status were more consistent, suggesting that better educated women and those from better-off households were consistently more likely to have experienced an abortion than other women. 


\section{CHAPTER 5}

\section{Abortion experiences}

This chapter explores the experiences of women who had undergone an abortion at any time in their life, and in the five years preceding the interview. If women reported more than one abortion, information is provided on their last abortion.

\section{Abortion-related decision-making}

The majority of women reported that the decision to undergo abortion was made by the woman jointly with her husband. However, state-wise differences were wide: four-fifths $(81 \%)$ of women in the two districts of Maharashtra who had undergone abortion so reported, compared to just half (54\%) of those in the two districts of Rajasthan. The leading decision-makers about the facility or provider from which abortion should be sought were also women along with their husband; again, those in the two districts of Maharashtra were considerably more likely than those in the two districts of Rajasthan to so report (76\% and $51 \%$, respectively). In both states, but particularly in Rajasthan, in-laws were significant decision-makers, both with regard to undergoing an abortion (16\% and 35\% in the Maharashtra and Rajasthan sites, respectively) and with regard to the selection of the provider or facility (15\% and 38\%, respectively). While few women in both states reported that they had made the decision entirely on their own about either of these issues (7-10\%), a large proportion of women

\section{Table 5.1}

Abortion-related decision-making: Percentage of women by person(s) making decision about abortion and selection of a successful abortion provider

\begin{tabular}{|c|c|c|c|c|}
\hline & $\begin{array}{l}\text { Aurangabad and } \\
\text { Jalna, Maharashtra }\end{array}$ & $\begin{array}{l}\text { Bundi and Tonk, } \\
\text { Rajasthan }\end{array}$ & $\begin{array}{c}\text { Aurangabad and } \\
\text { Jalna, Maharashtra }\end{array}$ & $\begin{array}{c}\text { Bundi and Tonk, } \\
\text { Rajasthan }\end{array}$ \\
\hline & \multicolumn{2}{|c|}{$\begin{array}{l}\text { Person(s) making the final decision } \\
\text { about whether to undergo abortion }{ }^{1}\end{array}$} & \multicolumn{2}{|c|}{$\begin{array}{l}\text { Person(s) making the final decision } \\
\text { about provider for abortion }{ }^{1}\end{array}$} \\
\hline Self alone & 6.8 & 7.4 & 9.4 & 10.2 \\
\hline Husband alone & 5.9 & 25.9 & 10.3 & 25.5 \\
\hline Jointly with husband & 81.1 & 53.7 & 75.5 & 50.7 \\
\hline Parents & 7.4 & 8.8 & 5.6 & 11.1 \\
\hline In-laws & 16.2 & 35.0 & 15.0 & 38.0 \\
\hline Private doctor & 15.4 & 6.5 & 1.2 & 0.5 \\
\hline Government doctor/health personnel & 2.4 & 7.9 & 0.3 & 0.9 \\
\hline Friend & 0.9 & 1.4 & -- & -- \\
\hline Other & 0.3 & 0.9 & 1.5 & 0.5 \\
\hline $\begin{array}{l}\text { Number who had experienced an } \\
\text { abortion }\end{array}$ & 345 & 221 & $345^{2}$ & 221 \\
\hline
\end{tabular}

Note: All Ns are unweighted.

${ }^{1}$ Multiple responses possible; ${ }^{2}$ Missing information from 3 women. 
in the Rajasthan settings (26\%) reported that the husband alone had made these decisions. Indeed, the relatively larger percentages of women in the Rajasthan settings than the Maharashtra settings reporting that their in-laws or husband had made the final decision about whether to undergo abortion and the abortion provider or facility reflects the far more limited autonomy of women in Rajasthan than in Maharashtra. Notably, some $18 \%$ of women in Aurangabad and Jalna, Maharashtra, and 14\% of those in Bundi and Tonk, Rajasthan, who had ever had an abortion reported that a doctor had recommended that the woman undergo abortion.

\section{Experience of second-trimester abortion}

The majority of women who underwent an abortion reported terminating their pregnancy in the first trimester. However, as shown in Table 5.2, a disturbingly large minority- $27 \%$ of those in the two districts of Maharashtra and 32\% of those in the two districts of Rajasthan who had ever had an abortion, and somewhat fewer of those who

Table 5.2

Timing of abortion: Percentage of women reporting a second-trimester abortion by background characteristics

\begin{tabular}{|c|c|c|c|c|}
\hline & \multicolumn{2}{|c|}{$\begin{array}{l}\text { All women who ever experienced } \\
\text { abortion }\end{array}$} & \multicolumn{2}{|c|}{$\begin{array}{l}\text { Women who experienced abortions } \\
\text { in the previous five years }\end{array}$} \\
\hline & $\begin{array}{l}\text { Aurangabad } \\
\text { and Jalna, } \\
\text { Maharashtra }\end{array}$ & $\begin{array}{c}\text { Bundi and Tonk, } \\
\text { Rajasthan }\end{array}$ & $\begin{array}{c}\text { Aurangabad } \\
\text { and Jalna, } \\
\text { Maharashtra }\end{array}$ & $\begin{array}{l}\text { Bundi and Tonk, } \\
\text { Rajasthan }\end{array}$ \\
\hline $\begin{array}{l}\text { Women reporting second-trimester } \\
\text { abortion }\end{array}$ & 27.4 & 31.8 & 20.7 & 23.5 \\
\hline \multicolumn{5}{|l|}{ Current age } \\
\hline $15-24$ & 19.0 & 35.5 & 16.5 & 26.3 \\
\hline $25-29$ & 28.6 & 32.2 & 24.1 & 22.6 \\
\hline $30-39$ & 35.3 & 30.4 & 33.3 & 25.0 \\
\hline \multicolumn{5}{|l|}{ Educational attainment levels } \\
\hline None & 41.2 & 33.6 & 31.1 & 22.6 \\
\hline $1-7$ & 26.2 & 23.7 & 21.3 & * \\
\hline $8-9$ & 23.3 & 45.5 & 14.3 & * \\
\hline $10+$ & 11.9 & 15.8 & 13.0 & * \\
\hline \multicolumn{5}{|l|}{ Household economic status } \\
\hline Low & 51.9 & 36.1 & 46.4 & 21.4 \\
\hline Medium & 27.2 & 33.8 & 17.8 & 40.9 \\
\hline High & 16.7 & 27.1 & 12.9 & 14.3 \\
\hline $\begin{array}{l}\text { Number who experienced a } \\
\text { second-trimester abortion }\end{array}$ & 345 & 221 & 182 & 89 \\
\hline
\end{tabular}

Note: All Ns are unweighted.

*Percentages not shown, based on fewer than 25 unweighted cases. 


\section{Table 5.3}

Experience of multiple abortions: Percentage of women reporting multiple abortions by background characteristics

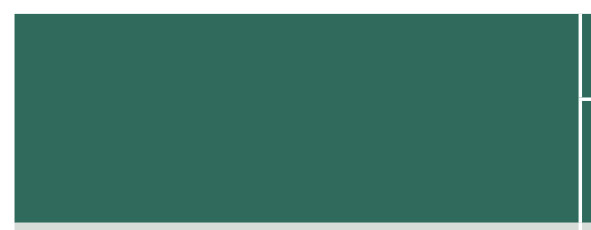

Women reporting multiple abortions

\section{Current age}

$15-24$

25-29

30-39

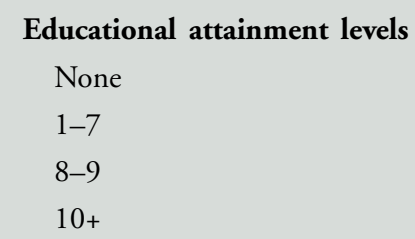

Household economic status

Low

Medium

High

Number who had experienced an abortion

\begin{tabular}{|c|c|}
\hline \multicolumn{2}{|c|}{$\begin{array}{c}\text { All women who ever experienced } \\
\text { abortion }\end{array}$} \\
\hline $\begin{array}{l}\text { Aurangabad } \\
\text { and Jalna, } \\
\text { Maharashtra }\end{array}$ & $\begin{array}{l}\text { Bundi and Tonk, } \\
\text { Rajasthan }\end{array}$ \\
\hline
\end{tabular}

18.3

13.1

20.4

21.8

12.6

21.4

11.6

23.9

11.1

22.9

15.1

345
19.0

6.5

21.7

20.8

18.2

13.2

22.7

26.3

11.5

20.3

23.5

221
Women who experienced abortions in the previous five years

\begin{tabular}{c|c}
\hline $\begin{array}{c}\text { Aurangabad } \\
\text { and Jalna, } \\
\text { Maharashtra }\end{array}$ & $\begin{array}{c}\text { Bundi and Tonk, } \\
\text { Rajasthan }\end{array}$ \\
\hline
\end{tabular}

18.9

24.7

13.7

10.5

20.8

30.0

33.3

27.8

8.9

23.0

18.5

23.4

10.7

10.3

23.3

36.4

16.1

31.4

182

Note: All Ns are unweighted.

*Percentage not shown, based on fewer than 25 unweighted cases.

had had a recent termination (21-24\%) —had undergone a second-trimester abortion. Secondtrimester abortions were more likely to be reported by the poorly educated and women from households with low economic status than other women. Age differences were evident in the Maharashtra settings, with older women more likely than younger women to report a second-trimester abortion; differences were negligible in the Rajasthan settings.

\section{Experience of multiple abortions}

The majority of women who had experienced abortion had done so just once. However, as evident from Table 5.3, $18-19 \%$ of women who had ever undergone an abortion and $19-25 \%$ of those who had experienced a recent abortion reported that they had undergone more than one abortion over the course of their life. Differences by age, educational 
attainment levels and household economic status were inconsistent, suggesting that multiple abortions are likely to be experienced by considerable proportions of all women, irrespective of age, educational level and economic status.

\section{Providers from whom abortion was sought}

The survey probed the pathways undertaken to terminate the pregnancy. Women were first asked whether they had done anything on their own to terminate the pregnancy, whether a family member or friend had done anything to terminate the woman's pregnancy, or whether they had sought the services of an informal provider. They were also probed about whether they had sought the services of a trained provider, the total number of providers from whom they had sought to terminate their pregnancy, the method used for the successful termination, and for those who sought care from a trained or untrained provider, the time taken to reach that provider.

Findings, presented in Table 5.4, indicate that a considerable minority of women who had

\section{Table 5.4}

Providers from whom abortion was sought: Percentage of women by individual from whom abortion was sought (successfully or unsuccessfully) and number of providers approached for abortion

\begin{tabular}{|c|c|c|c|c|}
\hline & \multicolumn{2}{|c|}{$\begin{array}{c}\text { All women who ever experienced } \\
\text { abortion }\end{array}$} & \multicolumn{2}{|c|}{$\begin{array}{l}\text { Women who experienced } \\
\text { abortions in the previous five } \\
\text { years }\end{array}$} \\
\hline & $\begin{array}{l}\text { Aurangabad } \\
\text { and Jalna, } \\
\text { Maharashtra }\end{array}$ & $\begin{array}{l}\text { Bundi } \\
\text { and Tonk, } \\
\text { Rajasthan }\end{array}$ & $\begin{array}{l}\text { Aurangabad } \\
\text { and Jalna, } \\
\text { Maharashtra }\end{array}$ & $\begin{array}{l}\text { Bundi } \\
\text { and Tonk, } \\
\text { Rajasthan }\end{array}$ \\
\hline $\begin{array}{l}\text { Untrained individuals from whom abortion } \\
\text { (successful or unsuccessful) was sought: }{ }^{1}\end{array}$ & 10.9 & 11.1 & 12.8 & 10.6 \\
\hline Untrained provider & 0.9 & 8.3 & 0.6 & 7.1 \\
\hline Chemist & 10.0 & 2.3 & 12.2 & 3.5 \\
\hline Family members/friends & 1.2 & 0.0 & 1.7 & 0.0 \\
\hline Self & 3.8 & 0.5 & 2.2 & 1.2 \\
\hline \multicolumn{5}{|l|}{$\begin{array}{l}\text { Number of providers from whom abortion was } \\
\text { sought (successful or unsuccessful) }\end{array}$} \\
\hline $\begin{array}{l}\text { None (abortion conducted by woman or family } \\
\text { members) }\end{array}$ & 0.9 & 0.0 & 0.6 & 0.0 \\
\hline One & 89.1 & 91.2 & 89.4 & 90.6 \\
\hline Two & 10.0 & 8.3 & 10.0 & 8.2 \\
\hline Three & 0.0 & 0.5 & 0.0 & 1.2 \\
\hline Number who had experienced an abortion & 345 & 221 & 182 & 89 \\
\hline
\end{tabular}

Note: All Ns are unweighted.

${ }^{1}$ Multiple responses possible. 
both ever experienced an abortion and experienced a recent termination (11-13\% in each state) had either attempted to terminate the pregnancy on their own or with the help of a family member or friend, or had approached an untrained provider or chemist. While $10-12 \%$ of women who had ever or recently experienced an abortion from the two districts of Maharashtra had approached a chemist for their abortion, just $2-4 \%$ of those from the two districts of Rajasthan had done so. In contrast, many more women from the Rajasthan sites than from the Maharashtra sites had approached an untrained provider $(7-8 \%$ versus $1 \%)$. A small proportion in each state $(4-5 \%$ and $1 \%$ of women who had ever or recently experienced an abortion in the surveyed settings of Maharashtra and Rajasthan, respectively) reported that they had attempted to terminate their pregnancy by themselves or that a family member or friend had helped the woman in doing so.

Women were asked about the number of providers from whom they had sought services. Most women replied that they had sought services from just one provider $(89 \%$ and $91 \%$ of those from the two districts of Maharashtra and Rajasthan, respectively). However, about one in ten women from both states had sought the services of more than one provider for terminating their pregnancy.

Table 5.5 shows that among successfully conducted abortions, most—but not all—were conducted by a doctor in the public or private sectors. For over $90 \%$ of women who reported ever or recently having experienced a successful abortion, the abortion had been conducted by a public or private sector provider or facility. In the two districts of Maharashtra, the large majority (85-88\%) reported that their abortions had been conducted by a private sector provider, with just $8-11 \%$ reporting that their pregnancy had been terminated in a District Hospital, a Rural Hospital or a PHC. In the two districts of Rajasthan, in contrast, half (50-51\%) reported that their pregnancy had been terminated in a public sector facility compared to two-fifths (40$41 \%)$ who reported a private sector provider. Finally, $3 \%$ and $9 \%$ of women in the Maharashtra and Rajasthan settings, respectively, reported that their pregnancy had been successfully terminated by a nurse or ANM, a traditional practitioner or through a chemist and hardly any (1\% and $0 \%$ from the two settings, respectively) reported that they themselves, or a friend or relative, had conducted their abortion.

With regard to the method used for pregnancy termination, women were asked whether their abortion had been terminated using surgical or medical methods. In order to distinguish between MVA and D\&C, we asked women who reported surgical abortion whether they had been made unconscious (given general anaesthesia for the surgical procedure) or not (MVA). We did not probe the nature of the oral medication taken and hence cannot confirm whether this was indeed the mifepristone-misoprostol combination or one of the many Ayurvedic and other preparations available. The vast majority- $81 \%$ and $85 \%$ of women from the Maharashtra and Rajasthan settings, respectively, who had ever had an abortion-reported the experience of surgical abortion. The majority likely had obtained a D\&C (that is, they reported that they had been made unconscious during the procedure (65\% and $77 \%$, respectively), whereas 


\section{Table 5.5}

Termination of pregnancy: Percentage of women by individual who conducted the abortion, method used and time taken to reach the facility where the pregnancy was successfully terminated

\begin{tabular}{|c|c|c|c|c|}
\hline & \multicolumn{2}{|c|}{$\begin{array}{l}\text { All women who ever } \\
\text { experienced abortion }\end{array}$} & \multicolumn{2}{|c|}{$\begin{array}{l}\text { Women who experienced } \\
\text { abortions in the previous five } \\
\text { years }\end{array}$} \\
\hline & $\begin{array}{l}\text { Aurangabad } \\
\text { and Jalna, } \\
\text { Maharashtra }\end{array}$ & $\begin{array}{c}\text { Bundi } \\
\text { and Tonk, } \\
\text { Rajasthan }\end{array}$ & $\begin{array}{l}\text { Aurangabad } \\
\text { and Jalna, } \\
\text { Maharashtra }\end{array}$ & $\begin{array}{l}\text { Bundi } \\
\text { and Tonk, } \\
\text { Rajasthan }\end{array}$ \\
\hline \multicolumn{5}{|l|}{ Facility/individual who conducted the abortion } \\
\hline Public sector doctor & 10.6 & 50.9 & 7.8 & 49.4 \\
\hline District Hospital & 5.6 & 27.3 & 4.5 & 27.1 \\
\hline CHC/Rural Hospital or PHC & 5.0 & 23.6 & 3.4 & 22.4 \\
\hline Private doctor & 85.3 & 40.3 & 87.7 & 41.2 \\
\hline Nurse/ANM & 0.0 & 6.0 & 0.0 & 5.9 \\
\hline Chemist & 2.9 & 1.4 & 3.9 & 3.5 \\
\hline Dai/TBA/herbalist/other traditional practitioner & 0.3 & 1.4 & 0.0 & 0.0 \\
\hline Self/Family members/friends & 0.9 & 0.0 & 0.6 & 0.0 \\
\hline \multicolumn{5}{|l|}{ Abortion method used } \\
\hline Surgery with general anaesthesia & 65.2 & 77.0 & 60.8 & 74.4 \\
\hline Surgery without general anaesthesia & 15.3 & 7.9 & 18.8 & 10.5 \\
\hline With pills (Medical abortion) & 9.4 & 5.1 & 12.2 & 8.1 \\
\hline Injections & 7.7 & 9.7 & 6.1 & 7.0 \\
\hline Vaginal herbs/roots/foreign bodies & 0.9 & 0.5 & 0.6 & 0.0 \\
\hline Ayurved medicines & 0.9 & 0.0 & 1.1 & 0.0 \\
\hline Homemade concoction & 0.6 & 0.0 & 0.6 & 0.0 \\
\hline \multicolumn{5}{|l|}{ Distance from provider ${ }^{1}$} \\
\hline Provider located nearby & 19.6 & 15.7 & 21.2 & 16.5 \\
\hline Provider located more than one hour away & 42.0 & 55.3 & 42.5 & 51.8 \\
\hline Number who had experienced an abortion & 345 & 221 & 182 & 89 \\
\hline
\end{tabular}

Note: All Ns are unweighted.

${ }^{1} 3$ women from Maharashtra who had ever successfully terminated a pregnancy by themselves or with help from a relative or friend, and 1 woman from Maharashtra who had done so in the last 5 years were excluded. 


\section{Table 5.6}

Source(s) of information about the abortion provider: Percentage of women by sources of information on successful abortion provider (trained or untrained)

\begin{tabular}{l|c|c|} 
& Aurangabad and Jalna, \\
Maharashtra & $\begin{array}{c}\text { Bundi and Tonk, } \\
\text { Rajasthan }\end{array}$ \\
\hline Source(s) of information ${ }^{1}$ & 33.6 & 62.0 \\
Husband & 45.8 & 60.6 \\
Family member/relative & 13.7 & 6.5 \\
Friend & 15.2 & 8.3 \\
Health worker & 2.1 & 0.9 \\
Saw the sign board & 0.6 & 0.0 \\
Mass media & 3.4 & 1.9 \\
Other & & $\mathbf{2 2 1}$ \\
Number who had experienced an & $\mathbf{3 4 2}$ &
\end{tabular}

Note: All Ns are unweighted.

${ }^{1}$ Multiple responses possible.

${ }^{2}$ Excludes women whose abortion was conducted by themselves, a family member or friend.

$15 \%$ and $8 \%$, respectively, likely had experienced

MVA (were not made unconscious during the procedure). We note that slightly more women who had undergone an abortion in the recent past reported a likely MVA (19\% and 11\%, respectively). In comparison, few women had terminated their pregnancy using oral medication: $9 \%$ and $5 \%$ of those who had ever terminated a pregnancy, and slightly more $(12 \%$ and $8 \%$ ) of those who had terminated their pregnancy in the five years preceding the interview. A small proportion (1-2\% in Maharashtra and $0-0.5 \%$ in Rajasthan) of women who had ever or recently experienced abortion reported terminating their pregnancy by inserting herbs and objects into the vagina, taking Ayurvedic medicines or consuming homemade concoctions.

Women reporting a successful abortion provided by a trained or untrained provider were also probed about physical access to that provider.
Clearly, abortion facilities were difficult to reach for many. Just $16-21 \%$ of women who had ever or recently experienced an abortion reported that the provider or facility was located in the same area as their residence. More than two in five (42\%) women in the two districts of Maharashtra and over half (55\%) of those in the two districts of Rajasthan who had ever experienced an abortion reported that it took them more than one hour to reach the facility or provider. Women experiencing an abortion in the recent past reported a similar pattern.

\section{Sources of information about provider}

All women who had undergone an abortion were asked who had told them about the provider who conducted their abortion. As shown in Table 5.6, for most women-34-46\% in the two districts of Maharashtra and $61-62 \%$ in the two districts of Rajasthan-it was the husband or other family 
member who was the source of information. In contrast, health workers were cited as a source of information relatively infrequently, by just $15 \%$ of women in the Maharashtra settings and $8 \%$ of those in the Rajasthan settings. The media were never cited as a source of information among women in the Rajasthan settings and by just $1 \%$ of those in the Maharashtra settings.

\section{Cost of services}

Women who had sought services from formal or non-formal sector providers were asked about the cost of the services they received, including fees and costs of medication and tests. Findings, presented in Table 5.7, suggest that abortion costs were high: one-third $(34 \%)$ of women who had undergone abortion in the two districts of Maharashtra and almost half (48\%) of those who had undergone abortion in the two districts of Rajasthan had paid more than Rs 1,000 for the service. Despite the fact that more women from the Rajasthan settings than the Maharashtra settings had sought services from the public sector, the average costs incurred were greater in the Rajasthan than in the Maharashtra settings: indeed, while abortion seekers from Aurangabad and Jalna, Maharashtra, paid, on average, Rs 747, those from Bundi and Tonk, Rajasthan, paid an average of Rs 888 for the service. Indeed, earlier studies had also documented the considerable costs incurred by women for an abortion (Rs 800 by rural women in Alwar district, Rajasthan, Elul et al., 2004).

\section{Quality of care}

The survey explored women's experiences with regard to a range of quality of care indicators. Findings are presented in Table 5.8. While one-third (31\%) and two-fifths of women from the surveyed districts of Maharashtra and Rajasthan, respectively, who had ever experienced an abortion were very satisfied with the

\section{Table 5.7}

Cost of abortion services: Percent distribution of women by costs incurred for the abortion procedure

\begin{tabular}{l|c|c|} 
& $\begin{array}{c}\text { Aurangabad and Jalna, } \\
\text { Maharashtra }\end{array}$ & $\begin{array}{c}\text { Bundi and Tonk, } \\
\text { Rajasthan }\end{array}$ \\
\hline Costs incurred for the abortion procedure (in Rs) & & 1.4 \\
0 & & 2.8 \\
$1-100$ & 4.5 & 18.4 \\
$101-500$ & 28.5 & 20.7 \\
$501-1000$ & 26.1 & 47.5 \\
$1001+$ & 33.8 & 9.2 \\
DK/missing & 5.3 & $\mathbf{1 0 0 . 0}$ \\
Total & $\mathbf{1 0 0 . 0}$ & $\mathbf{2 2 1}$ \\
Number who had experienced an abortion & $\mathbf{3 4 2}$ &
\end{tabular}

Note: All Ns are unweighted.

${ }^{1}$ Excludes women whose abortion was conducted by themselves, a family member or friend. 


\section{Table 5.8}

Quality of care provided by the successful provider: Percentage of women by indicators of quality of abortion-related care obtained

\begin{tabular}{|c|c|c|}
\hline & $\begin{array}{c}\text { Aurangabad and Jalna, } \\
\text { Maharashtra }\end{array}$ & $\begin{array}{c}\text { Bundi and Tonk, } \\
\text { Rajasthan }\end{array}$ \\
\hline \multicolumn{3}{|l|}{ Women reporting: } \\
\hline \multicolumn{3}{|l|}{ Satisfaction with the provider } \\
\hline Very satisfied & 31.3 & 39.8 \\
\hline Satisfied & 57.4 & 57.9 \\
\hline Would seek abortion services again if needed/recommend to others & 76.2 & 81.6 \\
\hline Provider treated the respondent (very) well & 73.2 & 59.9 \\
\hline $\begin{array}{l}\text { Of those have contact with other staff in the clinic: other staff in } \\
\text { the clinic treated the respondent (very) well }{ }^{1}\end{array}$ & 66.5 & 54.0 \\
\hline Provider gave enough time to respondent to explain her problem & 80.7 & 96.8 \\
\hline Provider understood problem/situation explained by respondent & 90.5 & 97.7 \\
\hline Provider clearly explained the procedure & 64.3 & 82.9 \\
\hline $\begin{array}{l}\text { Provider checked whether the respondent understood the } \\
\text { instruction/ procedure }\end{array}$ & 64.0 & 87.5 \\
\hline Provider was helpful in addressing respondent's problem & 72.0 & 85.0 \\
\hline Provider gave enough privacy to respondent & 84.5 & 88.0 \\
\hline Provider talked about post-abortion contraception & 36.6 & 40.3 \\
\hline Provider required husband's consent & 92.6 & 82.9 \\
\hline $\begin{array}{l}\text { Provider or facility forced woman to accept contraception as a } \\
\text { condition for abortion }\end{array}$ & 6.5 & 14.3 \\
\hline Number who had experienced an abortion & $342^{2}$ & 221 \\
\hline
\end{tabular}

Note: All Ns are unweighted.

${ }^{1} 245$ and 177 women in Maharashtra and Rajasthan, respectively.

${ }^{2}$ Excludes 3 women whose abortion was conducted by themselves, a family member or friend.

services received, the majority-about

three-fifths (57-58\%) of women from both stateswere somewhat satisfied. While three-quarters (73\%) of the women from the Maharashtra settings reported that the provider had treated them very well, somewhat fewer-three-fifths (60\%) —of those from the Rajasthan settings so reported. Further, somewhat fewer respondents reported that other staff at the facility had treated them well, and again, women from the Maharashtra settings were more likely than those from the Rajasthan settings to so report $(67 \%$ versus 54\%). Larger percentages of women (76-82\%) in both states reported that they would return to the same facility if they needed an abortion in the future or would recommend the provider to others.

Women were also asked whether the provider had given them enough time to explain their problem, explained the procedure to them and given them enough privacy during their interaction and the procedure. Most women reported that the 
provider had given them enough time to explain their problem, understood their problem and was helpful; even so, considerably more women from the two districts of Rajasthan than the two districts of Maharashtra reported satisfaction with all these matters (83-98\% versus 64-91\%).

While large proportions of women who had experienced abortion were satisfied with the services received, and while indeed, many reported that they were given enough information, time and privacy, quality of care was lacking in two important respects. First, the overwhelming majority reported that the provider had required the consent of their husband, a procedure not required under the Act: indeed, almost all women from Aurangabad and Jalna (93\%), and slightly fewer from Bundi and Tonk (83\%) so reported. Second, few women-about two in five (37-40\%) from each state-reported that the provider had counselled them about adopting a method of contraception.

Finally, relatively few women reported that the provider or facility had forced them to adopt a method of contraception as a condition for providing the abortion: $7 \%$ of women from Aurangabad and Jalna, Maharashtra, and 14\% from Bundi and Tonk, Rajasthan.

\section{Post-abortion morbidity}

Table 5.9 provides reported post-abortion complications and the facility where such complications were treated as reported by women who had ever undergone abortion and those who had undergone abortion in the five years prior to the interview. Findings suggest considerable state-wise differences in reporting. In all, among women who had experienced abortion in the five years prior to the interview (less subject to recall bias than those reporting ever having experienced an abortion), $48 \%$ in the Maharashtra settings and $17 \%$ in the Rajasthan settings reported experiencing one or more post-abortion complications. The most frequently reported complications in the surveyed districts of both Maharashtra and Rajasthan were backache (31\% and $6 \%$, respectively), and abdominal pain/ cramps, and fatigue and weakness (both, 25\% and $6 \%$, respectively). Symptoms of serious complications were less likely to be reported, and state-wise differences were narrower. For example, $2 \%$ of women from the two districts of Rajasthan and not a single woman in the two districts of Maharashtra reported symptoms suggestive of perforation of the uterus; just $3-4 \%$ of women from both states reported high-grade fever; $0-3 \%$ reported foul smelling discharge, perhaps symptoms of sepsis; and 6-11\% and $2-4 \%$ reported persistent bleeding for 2-4 weeks and more than four weeks, respectively. A generally similar picture emerged when women who had undergone abortion more than five years ago were also included.

Table 5.9 also presents the care seeking behaviour of women who experienced post-abortion complications. Findings indicate that among women who had experienced one or more complications, just half (51-55\%) of those in Aurangabad and Jalna, Maharashtra and about two-fifths $(36 \%$ of those who had ever experienced an abortion, and 6 of 14 of those who had recently experienced an abortion) in Bundi and Tonk, Rajasthan, had sought care for the complication, similar to rates reported in 


\section{Table 5.9}

Post-abortion morbidity: Percentage of women by post-abortion morbidity experienced

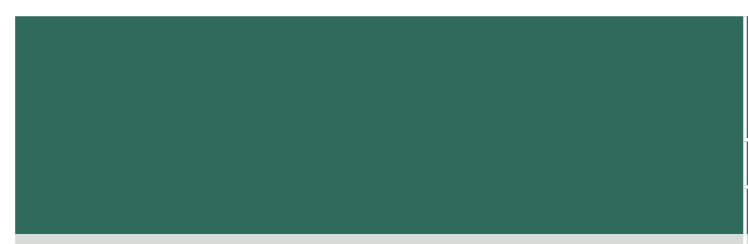

\begin{tabular}{|c|c|c|}
$\begin{array}{c}\text { Aurangabad } \\
\text { and Jalna, } \\
\text { Maharashtra }\end{array}$ & $\begin{array}{c}\text { Bundi } \\
\text { and Tonk, } \\
\text { Rajasthan }\end{array}$ & $\begin{array}{c}\text { Aurangabad } \\
\text { and Jalna, } \\
\text { Maharashtra }\end{array}$ \\
\hline
\end{tabular}

Bundi and Tonk,

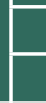

\section{Post-abortion morbidity ${ }^{1}$}

None

Backache

Abdominal pain/cramps

Maharashtra

Rajasthan

Fatigue and weakness

Persistent bleeding for two to four weeks

Persistent bleeding for more than four weeks

Abortions experienced during:

Foul smelling discharge

\begin{tabular}{|c|c|c|c|}
\hline \multicolumn{2}{|c|}{ Lifetime } & \multicolumn{2}{|c|}{ Past five years } \\
\hline 46.6 & 14.8 & 48.3 & 16.5 \\
\hline 53.4 & 85.2 & 51.7 & 83.5 \\
\hline 28.4 & 3.2 & 30.6 & 5.9 \\
\hline 24.2 & 5.6 & 24.6 & 5.9 \\
\hline 26.8 & 6.0 & 25.0 & 5.9 \\
\hline 11.2 & 3.7 & 11.1 & 5.9 \\
\hline 3.8 & 0.9 & 3.9 & 2.4 \\
\hline 3.8 & 0.0 & 3.3 & 0.0 \\
\hline 5.9 & 1.4 & 3.3 & 3.5 \\
\hline 12.1 & 2.3 & 14.0 & 2.4 \\
\hline 0.0 & 0.9 & 0.0 & 2.4 \\
\hline 1.8 & 1.8 & 1.1 & 4.7 \\
\hline 1.5 & 0.0 & 1.1 & 0.0 \\
\hline 345 & 221 & 182 & 89 \\
\hline 50.6 & 35.5 & 54.7 & * \\
\hline 74.1 & 71.9 & 74.4 & * \\
\hline 18.4 & 15.6 & 15.1 & * \\
\hline 166 & 32 & 91 & 14 \\
\hline 84 & 12 & 50 & 6 \\
\hline 4 & 2 & 1 & 0 \\
\hline 2 & 1 & 1 & 1 \\
\hline 23 & 2 & 11 & 1 \\
\hline 29 & 5 & 13 & 2 \\
\hline
\end{tabular}

High-grade fever

Dizziness

Uterus perforation/rupture

Irregular menstruation

Psychological symptoms

Number who had experienced an abortion

Sought care

Complications affected the ability to do regular household work

Hospitalized for complications

Number who experienced complications

Of those who sought care: (n)

Facility where admitted

District Hospital

CHC/Rural Hospital or PHC

Private hospital

Number of women hospitalized for complications

Note: All Ns are unweighted.

${ }^{1}$ Multiple responses possible. 
the earlier study conducted in Rajasthan (45\%, Elul et al. 2004). Large proportions reported, moreover, that the complication had affected their ability to do regular housework $(74 \%$ of women from the two districts of Maharashtra and $72 \%$ and 12 of 14 women from the two districts of Rajasthan). Finally, in both states, about $15-18 \%$ of women who had experienced post-abortion complications had been hospitalized, again resembling rates reported in the earlier study in Rajasthan (13\%, Elul et al. 2004). As in the case of the procedure itself, most women from the Maharashtra settings had sought post-abortion care from the private sector, while those from the Rajasthan settings were more evenly distributed across the public and private sectors.

\section{Post-abortion contraception}

As seen in Table 5.10, about half of the women in the two districts of Maharashtra who had ever or recently experienced an abortion reported adopting post-abortion contraception (51-54\%); in contrast, while about half $(52 \%)$ of those in the two districts of Rajasthan who had experienced an abortion in

\section{Table 5.10}

Post-abortion contraception: Percentage of women by post-abortion contraceptive practice

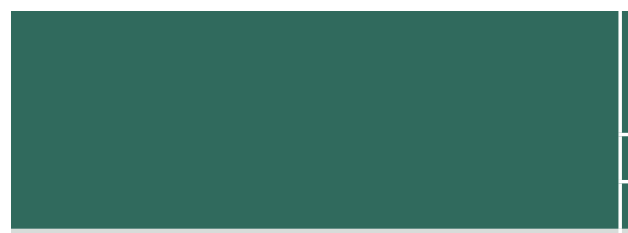

Number of women

Adopted post-abortion contraception

Post-abortion contraceptive methods

Male sterilization

Female sterilization

Pills

IUD

Condom

Injectables

Rhythm/spacing method

Withdrawal method

Used any permanent method

Used any modern non-terminal method

Of those who experienced abortion more than six months prior to interview:

$\%$ continuing non-terminal contraceptive method use for more than six months

\begin{tabular}{|c|c|c|c|}
\hline $\begin{array}{l}\text { Aurangabad } \\
\text { and Jalna, } \\
\text { Maharashtra }\end{array}$ & $\begin{array}{l}\text { Bundi and Tonk, } \\
\text { Rajasthan }\end{array}$ & $\begin{array}{l}\text { Aurangabad } \\
\text { and Jalna, } \\
\text { Maharashtra }\end{array}$ & $\begin{array}{l}\text { Bundi and Tonk, } \\
\text { Rajasthan }\end{array}$ \\
\hline \multicolumn{4}{|c|}{ Abortions experienced during: } \\
\hline \multicolumn{2}{|c|}{ Lifetime } & \multicolumn{2}{|c|}{$\begin{array}{l}\text { Past five years } \\
\end{array}$} \\
\hline 345 & 221 & 182 & 89 \\
\hline 51.0 & 35.2 & 53.9 & 51.8 \\
\hline 0.3 & 0.5 & 0.6 & 0.0 \\
\hline 15.0 & 11.1 & 10.1 & 11.8 \\
\hline 11.8 & 4.6 & 14.5 & 8.2 \\
\hline 5.6 & 0.5 & 6.7 & 0.0 \\
\hline 14.5 & 12.4 & 17.3 & 25.9 \\
\hline 0.0 & 0.5 & 0.0 & 0.0 \\
\hline 1.5 & 2.3 & 2.2 & 2.4 \\
\hline 2.4 & 3.7 & 2.2 & 3.5 \\
\hline 15.3 & 11.6 & 10.6 & 11.8 \\
\hline 31.9 & 18.0 & 38.5 & 34.1 \\
\hline$N=149$ & $\mathrm{~N}=72$ & $\mathrm{~N}=73$ & $\mathrm{~N}=40$ \\
\hline 79.7 & 93.0 & 84.7 & 87.2 \\
\hline
\end{tabular}

Note: All Ns are unweighted. 
the five years prior to the interview reported postabortion contraception, considerably fewer women (35\%) who had ever had an abortion so reported. Leading methods adopted were both terminal (female sterilization) and non-terminal (the condom and oral contraceptives), with women from the Maharashtra settings considerably more likely than their counterparts from the Rajasthan settings to have adopted non-terminal methods and somewhat more likely to have adopted terminal methods. Also notable is that among women who had experienced abortion (ever or in the five years preceding the interview) and had adopted a non-terminal method, four-fifths or more women from both Maharashtra and Rajasthan settings, continued to use the method for more than six months.

The link between contraceptive counselling and post-abortion contraception is apparent from Table 5.11. Indeed, as many as $68 \%$ of women from
Aurangabad and Jalna, Maharashtra, and $76 \%$ of women from Bundi and Tonk, Rajasthan, who had experienced abortion in the five years preceding the interview and had received contraceptive counselling reported adopting a method following abortion, compared to $44 \%$ and $30 \%$, respectively, of their counterparts who were not so counselled. Adoption of post-abortion contraception was also associated with other socio-demographic factors. In both states, older women were more likely than younger women to have adopted post-abortion contraception, those with at least one surviving son were correspondingly more likely to have done so than those without a surviving son; and those coming from better-off households were more likely to have done so than those in the poorest households. Differences by educational level were less consistent, but even so, those with any education were considerably more likely than uneducated women to have adopted postabortion contraception. 


\section{Table 5.11}

Counselling for post-abortion contraception: Percentage of women reporting post-abortion contraception by counselling status, sex combination of living children and background characteristics

\begin{tabular}{|c|c|c|}
\hline & $\begin{array}{l}\text { Aurangabad and Jalna, } \\
\text { Maharashtra }\end{array}$ & $\begin{array}{l}\text { Bundi and Tonk, } \\
\text { Rajasthan }\end{array}$ \\
\hline & \multicolumn{2}{|c|}{ Adopted post-abortion contraception } \\
\hline \multicolumn{3}{|c|}{$\begin{array}{l}\text { Of those experienced abortion during past five years and by } \\
\text { a provider: }\end{array}$} \\
\hline \multicolumn{3}{|c|}{ Status of contraceptive counselling } \\
\hline Counselled & 68.4 & 75.6 \\
\hline Not counselled & 43.7 & 29.5 \\
\hline \multicolumn{3}{|l|}{ Age of women } \\
\hline $15-24$ & 45.5 & 42.1 \\
\hline $25-29$ & 62.3 & 48.4 \\
\hline $30-39$ & 75.0 & 61.1 \\
\hline \multicolumn{3}{|c|}{ Sex combination of living children at abortion } \\
\hline At least one son & 58.8 & 58.7 \\
\hline Has no son & 39.5 & 31.8 \\
\hline \multicolumn{3}{|c|}{ Educational attainment level } \\
\hline None & 39.5 & 42.3 \\
\hline $1-7$ & 60.7 & $7 / 12$ \\
\hline $8-9$ & 63.0 & $7 / 10$ \\
\hline $10+$ & 54.3 & $9 / 12$ \\
\hline \multicolumn{3}{|c|}{ Household economic status } \\
\hline Low & 29.6 & 39.3 \\
\hline Medium & 53.9 & 40.9 \\
\hline High & 64.5 & 68.6 \\
\hline Number of women & 181 & 89 \\
\hline
\end{tabular}

Note: All Ns are unweighted. 


\section{Summary and conclusions}

Our community-based survey presents the perspectives and experiences of 4600 rural women in two purposively selected districts each of Maharashtra (Aurangabad and Jalna) and Rajasthan (Bundi and Tonk). Findings offer important insights into the levels of induced abortion in the sampled districts, the experiences of women undergoing abortions, and women's knowledge of the legality of abortion in India, and highlight that even as recently as 2006-07, women faced a number of barriers in obtaining safe abortion services. This chapter summarizes the main findings of the survey and discusses recommendations for programmes and policies.

\section{Knowledge about abortion}

A significant minority of women was not aware of the methods by which abortion is performed (17-19\%). Fewer women were aware of medical than surgical abortion; although between half and two-thirds of women interviewed in the two states reported awareness that abortion can be induced through oral medication, it is likely that not all of these women were referring to the mifepristonemisoprostol combination, but rather to the numerous traditional preparations available in their village or neighbouring villages.

\section{Awareness of abortion facilities and providers}

Large proportions of women (19-27\%) were unaware that abortion services were available at public or private sector facilities in their district, and at the same time, large proportions-onequarter from the two districts of Maharashtra and half from the two districts of Rajasthan-reported that abortion services were available from providers currently outside the provisions of the Act.

\section{Knowledge of the legality of abortion}

While the majority of women were aware of at least one situation in which abortion is legal in India, huge misconceptions remain about women's right to obtain abortion in a range of situations. For example, as many as half of women believed that abortion is not legally available to unmarried women or to those who have experienced contraceptive failure, and between one-third and two-fifths believed that abortion is not legally available to women whose health is endangered by the pregnancy or who have a strong chance of foetal malformation. And just 2-5\% of women were aware that women undergoing abortion do not require their husband's consent.

\section{Sources of abortion-related information}

Findings highlight that, aside from family members and friends, women had few sources of information about abortion. Indeed, few women-just $10-12 \%$ - had received information about abortion from health care providers, and just 6-8\% had received information from written materials, billboards or the television. 


\section{Preferences in selecting an abortion} facility

Evidence suggests that the availability of a female provider is an important factor for determining where a woman would seek abortion. Indeed, most women reported that they would seek abortion from a female doctor $(84-93 \%)$ or a nurse (11-26\%) rather than from a male doctor (4-8\%). Indeed, two-thirds of women would give importance to the availability of a female provider in selecting a facility for abortion; in comparison, issues such as assurances of privacy and the certification of the provider were far less likely to be cited as a key influencing factor.

\section{Sex-selective abortion}

The majority of women knew that foetal sex can be determined (84-85\%), and among those who knew so, about half believed that sex-determination was common in their community. Moreover, many knew or had heard of someone who had obtained a sex-selective abortion, and also knew a place where sex-determination tests are performed.

\section{Levels of abortion}

The prevalence of abortion was considerable in the sampled districts, with $11-13 \%$ of all women interviewed having experienced one or more abortions over their lifetime. Better educated women and those from economically better-off households were even more likely to have ever had an abortion, suggesting that the demand for abortion services is greater among these women than less educated and poorer women.
The abortion ratio ranged from 8 per 1,000 births in the Rajasthan settings to 11 per 1,000 in the Maharashtra settings in the five years prior to the interview, and 6-7 per 1,000 births over women's life more generally. These ratios are comparable with those obtained in previous community-based studies of abortion among rural women elsewhere in the country.

\section{Experience of second-trimester abortion}

Large proportions-between one-quarter and one-third-of women in the two states who had undergone an abortion had done so in their second trimester of pregnancy. Somewhat fewer women who had undergone an abortion in the five years prior to the interview reported a second-trimester abortion (between one-fifth and one-quarter) implying a trend towards early pregnancy termination. Notably, second-trimester abortions were considerably more likely to have been experienced by poorly educated women and those from poor households than other women.

\section{Repeat abortions}

Repeat abortions were fairly common among women in both states. Indeed, of those women who had ever experienced an abortion, about one-fifth had undergone more than one abortion over the course of their life.

\section{Abortion procedures and providers}

A number of women who had ever or recently experienced an abortion-11-13\% in the selected districts of both states-had attempted to induce 
the abortion themselves or with the help of a family member or friend, or had approached an informal or untrained provider, including nurses/ ANMs and chemists. Successful abortions had been performed, for the most part by doctors; however, $3-4 \%$ of women in the two districts of Maharashtra and $9 \%$ of those in the two districts of Rajasthan reported that their pregnancy had been terminated by a nurse/ANM or traditional practitioner or with medicines supplied by a chemist.

The majority of women who had ever or recently experienced an abortion had undergone surgical abortion (80-85\%). In contrast, just $9 \%$ and $5 \%$ of women from the Maharashtra and Rajasthan settings, respectively, who had ever undergone an abortion reported medical abortion; $12 \%$ and $8 \%$, respectively, of those who had undergone an abortion in the recent past so reported.

Physical access to facilities and providers was difficult. More than two-fifths of the women in the Maharashtra sites and more than half of those in the Rajasthan sites reported that they had travelled for more than an hour to reach the facility in which their abortion had been conducted.

\section{Quality of care}

The majority of women were satisfied with the services received. They reported that they had been given enough information, time and privacy by the provider, and indicated that they would return to the same facility if they needed an abortion in the future or would recommend the provider to others. Even so, one-quarter of women from the two districts of Maharashtra and two-fifths of those from the two districts of Rajasthan were not fully satisfied with the quality of care received from the provider, and onethird and half, respectively, were not fully satisfied with the quality of care provided by other staff at the facility.

Quality of care was lacking in important respects. First, the overwhelming majority reported that the provider had required the consent of their husband, a procedure not required under the Act: indeed, almost all women from the two districts of Maharashtra (93\%), and slightly fewer from the two districts of Rajasthan (83\%) so reported. Second, few women-just two in five from each state-reported that the provider had counselled them about adopting a method of contraception. Third, a small but disturbing minority of women- $7 \%$ from the two districts of Maharashtra and 14\% from the two districts of Rajasthan-reported that the provider or facility had forced them to adopt a method of contraception as a condition for providing them the abortion. Finally, abortion costs were significant: on average, women paid about Rs 700-800 for their abortion, and hardly any reported that the abortion was conducted completely free of charge.

\section{Post-abortion morbidity}

Considerably larger proportions of women who had ever or recently experienced an abortion from the Maharashtra settings than those in the Rajasthan settings reported the experience of postabortion complications (47-48\% versus $15-17 \%$ ). Symptoms of serious complications were, however, reported by relatively few women, and state-wise differences were narrow. For example, among women 
who had undergone abortion in the five years prior to the interview, $2 \%$ of women from Bundi and Tonk, Rajasthan, and not a single woman in Aurangabad and Jalna, Maharashtra, reported symptoms suggestive of perforation of the uterus; just $3-4 \%$ of women from the surveyed sites of both states reported high-grade fever and $0-3 \%$ reported foul smelling discharge, perhaps symptoms of sepsis; and $6-11 \%$ and $2-4 \%$ reported persistent bleeding for 2-4 weeks and more than four weeks, respectively. About three-quarters of women experiencing complications reported, moreover, that the complication affected their ability to do regular housework.

Not all women who experienced complications sought care. Of those who reported the experience of one or more complications, half of all women from the Maharashtra settings and two-fifths of those from the Rajasthan settings had sought care for the complication, similar to rates reported in the earlier study conducted in Rajasthan (45\%, Elul et al., 2004). Between one in six and one in seven women who had experienced abortion and reported postabortion complications had been hospitalized in both states, again resembling rates reported in the earlier study in Rajasthan (13\%, Elul et al., 2004).

\section{Post-abortion contraception}

Post-abortion contraception was far from universal; for example, just half of women in both states who had experienced abortion in the five years prior to the interview had adopted contraception following their abortion. Leading methods adopted were female sterilization and such non-terminal methods as the condom and oral contraceptives. Also notable is that among women who had experienced abortion (ever or in the five years preceding the interview) and had adopted a non-terminal method, four-fifths or more women from both Maharashtra and Rajasthan settings, continued to use the method for more than six months. Those who had adopted contraception differed from those who had not in significant ways: they were more likely to have received counselling, to be older, to have at least one surviving son and to come from better-off households.

\section{Recommendations}

Findings summarized above highlight that access to abortion remains limited for most women in the settings of Maharashtra and Rajasthan covered in this study. Policy and programmatic action is urgently required if access to safe abortion is to improve. A number of recommendations follow from the findings of this study:

Raise awareness at community level of women's right to abortion and location of services

Findings that misperceptions were widespread about the conditions under which abortion is legal and awareness was limited of the location of services call for efforts that spread information about these issues among rural women. Public information campaigns, and IEC and BCC programmes must educate women, their husbands and other family members about the legal right to abortion and the conditions under which abortion is legal. They must include information on abortion services and the location of health care facilities in which services may be 
obtained. In particular, such issues as women's right to obtain an abortion without her husband's consent must be stressed. Also important is to inform women about medical abortion, the importance of early terminations and the need to seek abortion from trained providers.

\section{Raise awareness among providers about legal issues surrounding abortion and improve their ability to provide sensitive counselling and care}

Findings that almost all women reported that the provider had required the husband's consent in order to perform an abortion, and a few reported that the provider had made post-abortion contraception a condition for performing the abortion suggest that providers are not fully conversant with the MTP Act. At the same time, the quality of care provided is not uniformly satisfactory; large proportions of women were required to pay heavily for the procedure and relatively few received post-abortion contraceptive counselling. Such findings call for a focus on the training of both medical officers and non-physician staff members of all abortion facilities in the provision of respectful abortion care and a more comprehensive understanding of the precise provisions of the MTP Act.

\section{Make abortion services more widely available in the public sector}

Findings have highlighted that large proportions of women travelled long distances to reach an abortion facility, especially in the two districts of Rajasthan, and that many women availed of private sector facilities, particularly in the two districts of Maharashtra. Clearly, there is a need to ensure that all CHCs and all upgraded PHCs are equipped to provide abortion services, namely that they contain trained personnel, and appropriate infrastructure, equipment and supplies.

Findings that few women were provided medical abortion and that many women reported post-abortion morbidities suggest that provider training and regular refresher training must be given that enables them to provide medical abortion effectively and upgrades skills in the provision of surgical abortion.

\section{Explore the feasibility of provision of abortion services by nurses}

Findings have highlighted the relative inaccessibility of abortion services: many women delayed the abortion into the second trimester, many sought abortion from untrained providers, and many travelled long distances to reach the abortion facility. Moreover, some women were reluctant to seek abortion services from male providers; for example, the large majority of women, especially in Rajasthan reported that they would opt for a female doctor, and more women would opt for a nurse than for a male doctor. Given that nurses are more likely than doctors to be available at peripheral health centres, and given the overwhelming evidence that trained nurses can provide abortion services that are safe, efforts must be made to expand the provider base to include nurses as well as doctors trained in nonallopathic systems of medicine. 


\section{References}

Barge S., M.E. Khan, S. Rajagopal et al. 1998. "Availability and quality of MTP services in Gujarat, Maharashtra, Tamil Nadu and Uttar Pradesh," Paper presented at the Global Meeting on Post-abortion Care and Operations Research, organised by Population Council, New York.

Barua A. and H. Apte. 2007. "Quality of abortion care: perspectives of clients and providers in Jharkhand," Economics and Political Weekly Vol 42(48): 71-80.

Chhabra, R. and S.C. Nuna. 1994. Abortion in India: An Overview. New Delhi: Ford Foundation.

Elul, B., S. Barge, S. Verma et al. 2004. Unwanted Pregnancy and Induced Abortion: Data from Men and Women in Rajasthan, India: Report. New Delhi: Population Council.

Ganatra, B. R. 2000. "Abortion research in India: What we know and what we need to know," in Women's Reproductive Health in India, eds. R. Ramasubban and S. Jejeebhoy. Jaipur: Rawat Publications.

Ganatra, B, S. Hirve, S. Karvande et al. 2008. "Induced abortions in rural western Maharashtra: Prevalence and patterns," in Reproductive Health in India: New Evidence, eds. M. Koenig, S. Jejeebhoy, J. Cleland and B. Ganatra. New Delhi: Rawat Publications.

Government of India (GOI). 1971. The Medical Termination of Pregnancy Act (Act. No. 34). New Delhi: Government of India.

International Institute for Population Sciences (IIPS). 2006. District Level Household Survey (DLHS-2), 2002-04: India. Mumbai: IIPS.

International Institute for Population Sciences (IIPS) and ORC Macro. 2000. National Family Health Survey (NFHS-2), 1998-99: India. Mumbai: IIPS.

International Institute for Population Sciences (IIPS) and Population Council. 2010. Youth in India: Situation and Needs, 2006-2007. Mumbai: IIPS.

Kalyanwala, S., A.J. Francis and S. Jejeebhoy. 2010. Public health facilities and women's access to abortion: A situation analysis in Maharashtra and Rajasthan. New Delhi, Population Council (unpublished report).

Malhotra, A., L. Nyblade, S. Parasuraman et al. 2003. Realizing Reproductive Choice and Rights: Abortion and Contraception in India. Report. Washington DC: International Council for Research on Women.

Office of the Registrar General, India. 2006. Sample Registration System, Maternal Mortality in India: 1997-2003 Trends, Causes and Risk Factors. New Delhi: Office of the Registrar General, India.

Office of the Registrar General and Census Commissioner. 2004. Primary Census Abstract: Total Population: Table $A-5$. New Delhi: Office of the Registrar General and Census Commissioner. 


\section{Appendices}

\section{Appendix 1}

Socio-demographic profile of respondents, respondent awareness and attitudes about abortion-related matters

\begin{tabular}{|c|c|c|c|c|}
\hline & Aurangabad & Jalna & Tonk & Bundi \\
\hline \multicolumn{5}{|l|}{ Characteristics of households } \\
\hline Resides in own home (\%) & 87.2 & 94.0 & 98.9 & 96.3 \\
\hline Mean number of usual household members & 5.2 & 5.2 & 5.5 & 5.2 \\
\hline Resides in a pucca structure (\%) & 32.5 & 28.4 & 29.4 & 23.6 \\
\hline Household own agricultural land (\%) & 66.8 & 71.0 & 81.2 & 72.6 \\
\hline Toilet facility: own flush toilet (\%) & 13.7 & 10.2 & 6.7 & 8.4 \\
\hline Source of lighting: Electricity (\%) & 70.0 & 71.7 & 52.2 & 45.9 \\
\hline $\begin{array}{l}\text { Source of drinking water: Own piped water/hand pump/ } \\
\text { covered well }(\%)\end{array}$ & 26.3 & 28.0 & 9.2 & 19.6 \\
\hline \multicolumn{5}{|l|}{ Economic status } \\
\hline Low & 33.3 & 35.7 & 44.8 & 51.5 \\
\hline Medium & 45.1 & 43.9 & 36.6 & 31.1 \\
\hline High & 21.3 & 20.2 & 18.6 & 17.4 \\
\hline Mean $(0-53)$ & 15.2 & 14.8 & 13.8 & 13.0 \\
\hline Number of households & 1,561 & 1,692 & 1,102 & 1,232 \\
\hline \multicolumn{5}{|l|}{ Profile of respondents } \\
\hline Mean current age & 25.4 & 25.9 & 26.9 & 28.0 \\
\hline Never attended school (\%) & 34.7 & 42.5 & 74.9 & 74.6 \\
\hline Completed Class 10 or higher (\%) & 19.5 & 11.9 & 4.9 & 4.8 \\
\hline Worked in the last year (\%) & 51.5 & 65.7 & 55.9 & 63.4 \\
\hline Mean number of children ever born & 2.3 & 2.4 & 2.4 & 2.6 \\
\hline Mean number of surviving children & 2.1 & 2.2 & 2.1 & 2.3 \\
\hline Women experienced at least one child death & 13.7 & 16.4 & 21.2 & 23.6 \\
\hline Number of women & 1,308 & 1,339 & 940 & 1,013 \\
\hline \multicolumn{5}{|l|}{ Awareness and practice of family planning (\%) } \\
\hline Aware of at least one terminal method & 95.1 & 99.6 & 98.3 & 99.8 \\
\hline Aware of at least one modern non-terminal method & 85.4 & 95.6 & 96.2 & 96.8 \\
\hline Ever use (any method) & 64.9 & 67.4 & 56.4 & 54.9 \\
\hline Ever use (any modern non-terminal method) & 30.5 & 27.7 & 22.0 & 16.3 \\
\hline Currently using any method & 55.7 & 57.3 & 49.5 & 51.1 \\
\hline Currently using terminal method & 40.4 & 44.1 & 35.6 & 39.5 \\
\hline Currently using non-terminal method & 12.8 & 9.7 & 7.8 & 6.6 \\
\hline Number of women & 1,308 & 1,339 & 940 & 1,013 \\
\hline
\end{tabular}

Cont'd on next page... 
Appendix 1: (Cont'd)

\begin{tabular}{|c|c|c|c|c|}
\hline & Aurangabad & Jalna & Tonk & Bundi \\
\hline Women correctly aware of: & & & & \\
\hline At least one condition under which abortion is legal & 71.9 & 83.6 & 70.7 & 76.5 \\
\hline Misperceptions held & & & & \\
\hline$\%$ of women who reported that it is illegal: & & & & \\
\hline For an unmarried woman to access abortion & 47.8 & 49.8 & 43.4 & 43.4 \\
\hline $\begin{array}{l}\text { For a woman whose pregnancy results from contraceptive } \\
\text { failure ("accidentally") to access abortion }\end{array}$ & 51.6 & 47.4 & 46.2 & 45.0 \\
\hline $\begin{array}{l}\text { For a woman whose pregnancy has resulted from rape to } \\
\text { access abortion }\end{array}$ & 41.4 & 39.0 & 47.6 & 36.4 \\
\hline $\begin{array}{l}\text { For a woman whose health is endangered by the pregnancy } \\
\text { to access abortion }\end{array}$ & 32.6 & 25.9 & 42.6 & 36.3 \\
\hline $\begin{array}{l}\text { If there is a strong chance of foetal malformation, for a } \\
\text { woman to access abortion }\end{array}$ & 37.8 & 29.4 & 41.5 & 37.4 \\
\hline $\begin{array}{l}\text { For a woman who is more than } 20 \text { weeks pregnant to access } \\
\text { abortion }\end{array}$ & 12.3 & 8.9 & 6.3 & 1.1 \\
\hline$\%$ women aware about consent procedures: & & & & \\
\hline $\begin{array}{l}\text { Misperceiving that a women undergoing abortion needs her } \\
\text { husband's consent }\end{array}$ & 87.4 & 89.2 & 96.1 & 97.9 \\
\hline $\begin{array}{l}\text { Aware that a woman undergoing abortion does not require } \\
\text { husband's consent }\end{array}$ & 5.8 & 4.2 & 2.4 & 1.4 \\
\hline Number of women & 1,308 & 1,339 & 940 & 1,013 \\
\hline Attitudes towards accessing abortion services & & & & \\
\hline $\begin{array}{l}\text { \% of women agree that a woman can access abortion if: } \\
\text { The woman's health is endangered by the pregnancy }\end{array}$ & 90.0 & 94.0 & 79.7 & 76.2 \\
\hline The woman is unmarried & 88.1 & 90.0 & 86.3 & 81.8 \\
\hline The pregnancy is a result of rape & 86.0 & 85.9 & 82.3 & 72.8 \\
\hline There is a strong chance of serious defect in the baby & 82.5 & 87.4 & 80.6 & 72.6 \\
\hline The woman does not want another child & 78.7 & 79.1 & 72.9 & 65.4 \\
\hline The woman cannot afford the child & 77.1 & 79.0 & 74.9 & 63.7 \\
\hline $\begin{array}{l}\text { The pregnancy is an accident (result of a contraceptive } \\
\text { failure) }\end{array}$ & 66.1 & 60.5 & 58.6 & 53.1 \\
\hline The foetus is female & 45.5 & 52.6 & 15.5 & 9.7 \\
\hline The foetus is male & 11.4 & 9.3 & 6.2 & 2.1 \\
\hline The woman is more than 20 weeks pregnant & 17.4 & 15.0 & 6.1 & 0.8 \\
\hline Number of women & 1,308 & 1,339 & 940 & 1,013 \\
\hline
\end{tabular}

Cont'd on next page... 


\begin{tabular}{|c|c|c|c|c|}
\hline & Aurangabad & Jalna & Tonk & Bundi \\
\hline \multicolumn{5}{|l|}{ Women's awareness about methods of safe abortion (\%) } \\
\hline Women reporting awareness of any method of abortion & 78.1 & 90.5 & 79.0 & 83.7 \\
\hline \multicolumn{5}{|l|}{ Women reporting awareness of specific methods* } \\
\hline Surgical method & 72.5 & 82.7 & 69.6 & 76.6 \\
\hline Medical Abortion & 43.7 & 58.5 & 64.1 & 62.8 \\
\hline Number of women & 1,308 & 1,339 & 940 & 1,013 \\
\hline \multicolumn{5}{|l|}{ Women's awareness about facilities providing abortion $^{1}(\%)$} \\
\hline $\begin{array}{l}\text { Awareness of public or private sector facilities/providers of } \\
\text { abortion services: }\end{array}$ & 71.1 & 74.8 & 79.0 & 84.3 \\
\hline Any public sector facility & 39.4 & 36.1 & 76.8 & 83.7 \\
\hline District Hospital & 29.2 & 28.2 & 45.3 & 66.4 \\
\hline $\mathrm{CHC} /$ Rural Hospital or PHC & 21.6 & 17.0 & 60.9 & 50.2 \\
\hline Private sector facility/doctor & 57.9 & 67.3 & 28.7 & 31.3 \\
\hline Awareness of other providers of abortion services & 20.3 & 29.8 & 47.1 & 49.7 \\
\hline ANM/Nurse & 1.5 & 1.9 & 16.6 & 15.8 \\
\hline Chemist & 19.3 & 28.4 & 36.5 & 46.7 \\
\hline Awareness only of likely unsafe sources of abortion & 3.1 & 4.0 & 4.0 & 3.4 \\
\hline Number of women & 1,308 & 1,339 & 940 & 1,013 \\
\hline \multicolumn{5}{|l|}{$\begin{array}{l}\text { Perceptions about where women in the community access } \\
\text { abortion: women reporting facilities from which women in } \\
\text { their community accessed abortion }{ }^{1}(\%)\end{array}$} \\
\hline Any public sector facility & 40.2 & 37.3 & 94.5 & 98.0 \\
\hline District Hospital & 30.9 & 31.1 & 60.4 & 84.7 \\
\hline CHC/Rural Hospital or PHC & 17.7 & 13.6 & 59.3 & 52.0 \\
\hline Private sector facility/doctor & 58.0 & 68.0 & 19.7 & 18.6 \\
\hline Other provider & 5.7 & 8.4 & 5.5 & 3.9 \\
\hline ANM/Nurse & 2.4 & 5.3 & 4.4 & 3.3 \\
\hline Chemist & 0.8 & 3.0 & 0.7 & 0.2 \\
\hline Dai/TBA/herbalist/other traditional practitioner & 2.1 & 1.0 & 0.0 & 0.1 \\
\hline Others & 0.9 & 0.3 & 0.5 & 0.5 \\
\hline Don't know & 20.9 & 15.0 & 2.7 & 0.8 \\
\hline Number of women & 1,308 & 1,339 & 940 & 1,013 \\
\hline
\end{tabular}


Appendix 1: (Cont'd)

\begin{tabular}{|c|c|c|c|c|}
\hline & Aurangabad & Jalna & Tonk & Bundi \\
\hline \multicolumn{5}{|l|}{ Sources of information about abortion (\%) } \\
\hline Did not receive any information & 67.0 & 58.3 & 63.9 & 72.4 \\
\hline \multicolumn{5}{|l|}{ Received information from: } \\
\hline Media & 6.0 & 5.6 & 7.3 & 7.9 \\
\hline Health care provider* & 9.5 & 11.1 & 12.1 & 11.7 \\
\hline Family member and friend & 25.6 & 34.2 & 27.2 & 19.1 \\
\hline At least any one of the above sources & 33.0 & 41.7 & 36.1 & 27.6 \\
\hline Number of women & 1,308 & 1,339 & 940 & 1,013 \\
\hline \multicolumn{5}{|l|}{$\begin{array}{l}\text { Perceptions about the facility/provider from which } \\
\text { women would seek abortion if unintended pregnancy is } \\
\text { experienced }(\%)\end{array}$} \\
\hline Female doctor & 81.3 & 88.6 & 90.2 & 96.6 \\
\hline Male doctor & 5.4 & 11.2 & 4.6 & 2.3 \\
\hline Nurse & 6.6 & 16.3 & 28.1 & 23.8 \\
\hline Female ayurved doctor & 1.1 & 2.6 & 0.4 & 0.2 \\
\hline Male ayurved doctor & 0.2 & 0.3 & 0.1 & 0.1 \\
\hline Dai & 1.0 & 1.9 & 1.0 & 0.6 \\
\hline Chemist & 0.5 & 1.3 & 0.9 & 0.2 \\
\hline Can’t say & 10.2 & 6.5 & 6.6 & 3.2 \\
\hline Number of women & 1,308 & 1,339 & 940 & 1,013 \\
\hline \multicolumn{5}{|l|}{$\begin{array}{l}\text { Factors important in selecting a provider for abortion (\%) } \\
\text { It is very important that: }\end{array}$} \\
\hline The clinic has a female provider & 65.1 & 67.3 & 70.6 & 67.0 \\
\hline If the facility is well equipped & 65.9 & 69.9 & 55.4 & 46.3 \\
\hline If the cost of the abortion is low & 55.0 & 55.1 & 51.6 & 52.0 \\
\hline If the facility is close to your home & 55.0 & 54.2 & 57.9 & 51.1 \\
\hline If the clinic ensures privacy & 48.2 & 48.9 & 40.9 & 35.8 \\
\hline If the provider is well known and has good reputation & 44.6 & 44.5 & 40.9 & 39.6 \\
\hline If the provider is legal & 49.9 & 49.3 & 31.0 & 26.7 \\
\hline $\begin{array}{l}\text { If the facility or provider does not require your } \\
\text { husband's consent }\end{array}$ & 24.8 & 5.9 & 23.6 & 10.7 \\
\hline $\begin{array}{l}\text { If post-abortion contraception is not made a condition } \\
\text { for abortion }\end{array}$ & 23.1 & 15.6 & 19.9 & 9.5 \\
\hline Number of women & 1,308 & 1,339 & 940 & 1,013 \\
\hline
\end{tabular}

Cont'd on next page... 


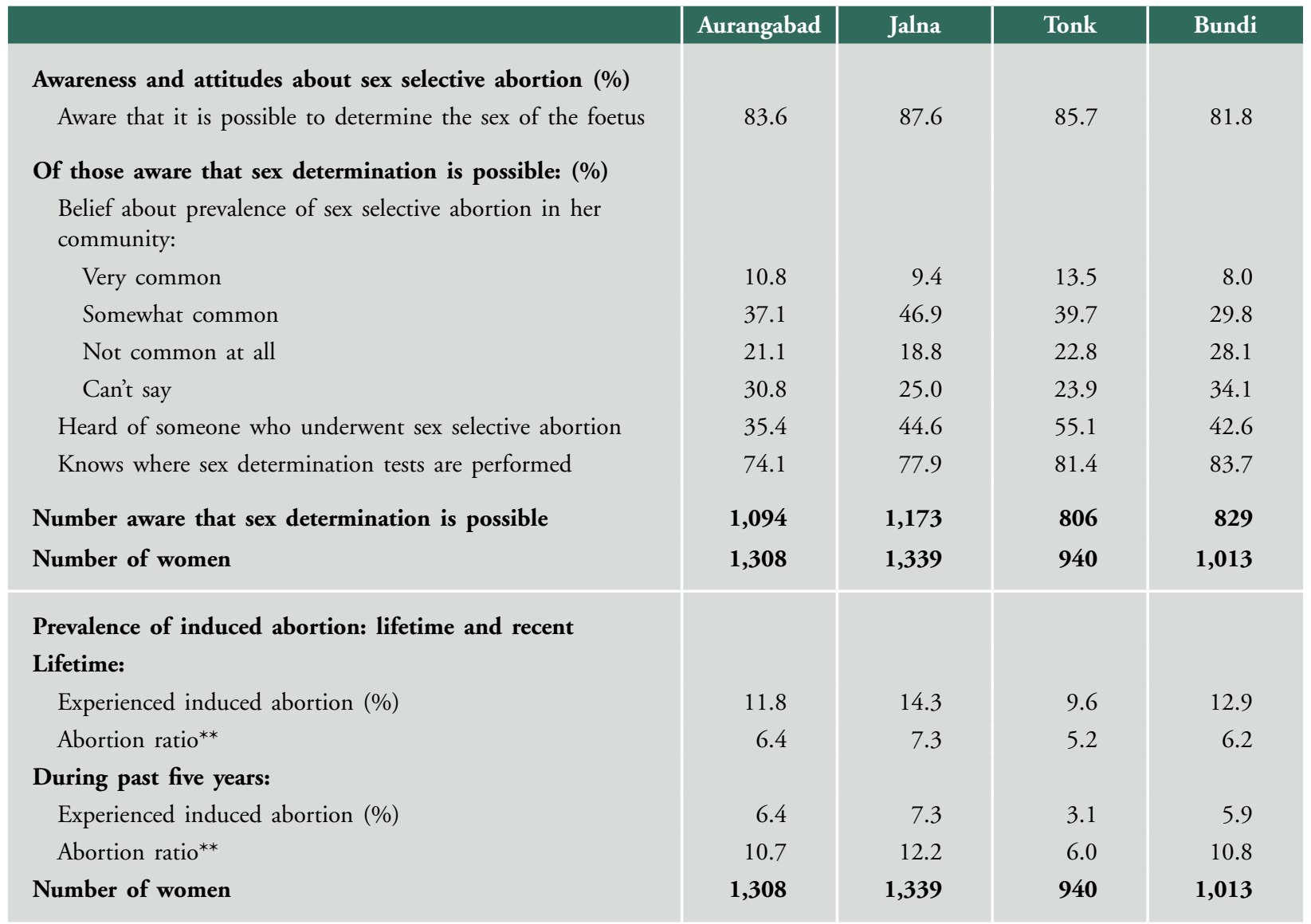

Note: All district level estimates presented in the appendix are unweighted.

${ }^{1}$ Multiple responses possible; *Includes $0.5 \%$ of women in Maharashtra who reported that a chemist provided information to them. **Abortions per 100 children ever born (Aurangabad=2,973, Jalna=3,159, Tonk=2,230, Bundi=2,618) and per 100 children ever born in the last five years (Aurangabad=973, Jalna=979, Tonk=669, Bundi=750). 


\section{Appendix 2}

Abortion-related decision making, women who had ever experienced abortion, by district

\begin{tabular}{|c|c|c|c|c|}
\hline & \multicolumn{4}{|c|}{ Abortion experiences } \\
\hline & \multicolumn{4}{|c|}{ All women who ever experienced abortion } \\
\hline & Aurangabad & Jalna & Tonk & Bundi \\
\hline \multicolumn{5}{|c|}{$\begin{array}{l}\text { Person(s) making the final decision about whether to } \\
\text { undergo abortion }(\%)\end{array}$} \\
\hline Self alone & 9.1 & 4.2 & 11.1 & 3.8 \\
\hline Husband alone & 8.4 & 2.6 & 14.4 & 36.6 \\
\hline Jointly with husband & 74.7 & 89.0 & 58.9 & 48.9 \\
\hline Parents & 10.4 & 3.7 & 6.7 & 10.7 \\
\hline In-laws & 14.3 & 18.3 & 28.9 & 40.5 \\
\hline Private doctor & 10.4 & 21.5 & 5.6 & 6.9 \\
\hline Government doctor/health personnel & 2.6 & 2.1 & 10.0 & 6.1 \\
\hline Friend & 0.6 & 1.0 & 2.2 & 0.8 \\
\hline Other & 0.0 & 0.5 & 1.1 & 0.8 \\
\hline Number who had experience abortion & 154 & 191 & 90 & 131 \\
\hline \multicolumn{5}{|c|}{$\begin{array}{l}\operatorname{Person}(s) \text { making the final decision about provider for } \\
\text { abortion }^{1}(\%)\end{array}$} \\
\hline Self alone & 13.0 & 5.2 & 10.0 & 10.7 \\
\hline Husband alone & 13.6 & 6.3 & 24.4 & 26.7 \\
\hline Jointly with husband & 69.5 & 82.7 & 47.8 & 53.4 \\
\hline Parents & 7.1 & 3.7 & 11.1 & 11.5 \\
\hline In-laws & 15.6 & 14.1 & 32.2 & 43.5 \\
\hline Private doctor & 1.3 & 1.0 & 0.0 & 0.8 \\
\hline Government doctor/health personnel & 0.6 & 0.0 & 1.1 & 0.8 \\
\hline Other & 0.6 & 2.6 & 0.0 & 0.8 \\
\hline Number who had experience abortion & 154 & 191 & 90 & 131 \\
\hline
\end{tabular}

${ }^{1}$ Multiple responses possible. 


\section{Appendix 3}

Abortion experiences, women who had ever had an abortion and those who had an abortion in the 5 years prior to the interview, by district

\begin{tabular}{|c|c|c|c|c|c|c|c|c|}
\hline & \multicolumn{8}{|c|}{ Abortion experiences } \\
\hline & \multicolumn{4}{|c|}{ All women who ever experienced abortion } & \multicolumn{4}{|c|}{$\begin{array}{l}\text { Women who experienced abortions in the } \\
\text { previous five years }\end{array}$} \\
\hline & $\begin{array}{l}\text { Auranga- } \\
\text { bad }\end{array}$ & Jalna & Tonk & Bundi & $\begin{array}{l}\text { Auranga- } \\
\text { bad }\end{array}$ & Jalna & Tonk & Bundi \\
\hline $\begin{array}{l}\text { Second-trimester and } \\
\text { multiple abortions: }(\%)\end{array}$ & & & & & & & & \\
\hline $\begin{array}{l}\text { Women reporting second- } \\
\text { trimester abortion }\end{array}$ & 26.0 & 29.3 & 28.9 & 34.4 & 20.2 & 21.4 & 20.7 & 25.0 \\
\hline $\begin{array}{l}\text { Women reporting multiple } \\
\text { abortion }\end{array}$ & 19.5 & 16.8 & 22.2 & 16.0 & 19.0 & 18.4 & 27.6 & 23.3 \\
\hline $\begin{array}{l}\text { Number who had experience } \\
\text { abortion }\end{array}$ & 154 & 191 & 90 & 131 & 84 & 98 & 29 & 60 \\
\hline $\begin{array}{l}\text { Providers from whom } \\
\text { abortion was sought: } \\
\% \text { of women by individual } \\
\text { from whom abortion was } \\
\text { sought (successfully or } \\
\text { unsuccessfully) and number } \\
\text { of providers approached for } \\
\text { abortion: }\end{array}$ & & & & & & & & \\
\hline $\begin{array}{l}\text { Untrained individuals from } \\
\text { whom abortion } \\
\text { (successful or } \\
\text { unsuccessful) was sought: }{ }^{1}\end{array}$ & 11.7 & 9.9 & 14.4 & 7.6 & 13.1 & 12.2 & 17.2 & 6.7 \\
\hline Untrained provider & 0.7 & 1.0 & 10.0 & 6.9 & 1.2 & 0.0 & 6.9 & 6.7 \\
\hline Chemist & 11.0 & 8.9 & 4.4 & 0.8 & 11.9 & 12.2 & 10.3 & 0.0 \\
\hline Family member/friend & 1.3 & 1.0 & 0.0 & 0.0 & 1.2 & 2.0 & 0.0 & 0.0 \\
\hline Self & 3.2 & 4.7 & 0.0 & 0.8 & 1.2 & 4.1 & 0.0 & 1.7 \\
\hline $\begin{array}{l}\text { Number of providers from } \\
\text { whom abortion was sought } \\
\text { (successful or unsuccessful) }\end{array}$ & & & & & & & & \\
\hline $\begin{array}{l}\text { None (abortion conducted } \\
\text { by woman or family } \\
\text { member) }\end{array}$ & 0.6 & 1.0 & 0.0 & 0.0 & 0.0 & 1.0 & 0.0 & 0.0 \\
\hline One & 88.3 & 90.1 & 88.9 & 93.9 & 90.5 & 88.8 & 82.8 & 95.0 \\
\hline Two & 11.0 & 8.9 & 11.1 & 5.3 & 9.5 & 10.2 & 17.2 & 3.3 \\
\hline Three & 0.0 & 0.0 & 0.0 & 0.8 & 0.0 & 0.0 & 0.0 & 1.7 \\
\hline $\begin{array}{l}\text { Number who had experience } \\
\text { abortion }\end{array}$ & 154 & 191 & 90 & 131 & 84 & 98 & 29 & 60 \\
\hline
\end{tabular}


Appendix 3: (Cont'd)

\begin{tabular}{|c|c|c|c|c|c|c|c|c|}
\hline & \multicolumn{8}{|c|}{ Abortion experiences } \\
\hline & \multicolumn{4}{|c|}{ All women who ever experienced abortion } & \multicolumn{4}{|c|}{$\begin{array}{l}\text { Women who experienced abortions in the } \\
\text { previous five years }\end{array}$} \\
\hline & $\begin{array}{l}\text { Auranga- } \\
\text { bad }\end{array}$ & Jalna & Tonk & Bundi & $\begin{array}{c}\text { Auranga- } \\
\text { bad }\end{array}$ & Jalna & Tonk & Bundi \\
\hline \multirow{2}{*}{\multicolumn{9}{|c|}{$\begin{array}{l}\text { Termination of pregnancy: } \\
\% \text { of women by individual } \\
\text { who conducted the abortion, } \\
\text { method used and time } \\
\text { taken to reach the facility } \\
\text { where the pregnancy was } \\
\text { successfully terminated }\end{array}$}} \\
\hline & & & & & & & & \\
\hline Public sector doctors & 10.3 & 10.5 & 52.2 & 49.7 & 7.2 & 9.2 & 58.6 & 43.3 \\
\hline District Hospital & 7.1 & 3.7 & 13.3 & 39.7 & 4.8 & 4.1 & 13.8 & 35.0 \\
\hline $\begin{array}{l}\text { CHC/Rural Hospital } \\
\text { or PHC }\end{array}$ & 3.2 & 6.8 & 38.9 & 9.9 & 2.4 & 5.1 & 44.8 & 8.3 \\
\hline Private doctor & 85.1 & 86.4 & 36.7 & 43.5 & 88.1 & 86.7 & 27.6 & 50.0 \\
\hline Nurse/ANM & 0.0 & 0.0 & 7.8 & 4.6 & 0.0 & 0.0 & 6.9 & 5.0 \\
\hline Chemist & 0.6 & 0.0 & 0.0 & 0.8 & 1.2 & 0.0 & 0.0 & 1.7 \\
\hline $\begin{array}{l}\text { Dai/TBA/herbalist/other } \\
\text { traditional practitioner }\end{array}$ & 0.0 & 0.5 & 1.1 & 1.5 & 0.0 & 0.0 & 0.0 & 0.0 \\
\hline Self/Family member/friend & 3.9 & 2.6 & 2.2 & 0.0 & 3.6 & 4.0 & 6.9 & 0.0 \\
\hline \multicolumn{9}{|l|}{ Abortion method used } \\
\hline $\begin{array}{l}\text { Surgery with general } \\
\text { anaesthesia }\end{array}$ & 66.9 & 63.4 & 71.1 & 82.4 & 60.7 & 61.2 & 58.6 & 85.0 \\
\hline $\begin{array}{l}\text { Surgery without general } \\
\text { anaesthesia }\end{array}$ & 13.6 & 17.3 & 11.1 & 4.6 & 19.0 & 18.4 & 20.7 & 3.3 \\
\hline $\begin{array}{l}\text { With pills (Medical } \\
\text { abortion) }\end{array}$ & 11.0 & 7.9 & 7.8 & 2.3 & 14.3 & 9.2 & 13.8 & 5.0 \\
\hline Injections & 6.5 & 8.9 & 8.9 & 10.7 & 4.8 & 8.2 & 6.9 & 6.7 \\
\hline $\begin{array}{l}\text { Vaginal herbs/roots/foreign } \\
\text { bodies }\end{array}$ & 0.6 & 1.0 & 0.0 & 0.0 & 0.0 & 1.0 & 0.0 & 0.0 \\
\hline Ayurved medicines & 1.3 & 0.5 & 0.0 & 0.0 & 1.2 & 1.0 & 0.0 & 0.0 \\
\hline Homemade concoction & 0.0 & 1.0 & 1.1 & 0.0 & 0.0 & 1.0 & 0.0 & 0.0 \\
\hline \multicolumn{9}{|l|}{ Distance from provider ${ }^{2}$} \\
\hline Provider located nearby & 25.3 & 12.6 & 14.4 & 16.8 & 28.6 & 11.2 & 17.2 & 16.7 \\
\hline $\begin{array}{l}\text { Provider located more than } \\
\text { one hour away }\end{array}$ & 37.7 & 46.1 & 52.2 & 58.0 & 39.3 & 45.9 & 34.5 & 63.3 \\
\hline $\begin{array}{l}\text { Number who had experience } \\
\text { abortion }\end{array}$ & 154 & 191 & 90 & 131 & 84 & 98 & 29 & 60 \\
\hline
\end{tabular}


Appendix 3: (Cont'd)

\begin{tabular}{|c|c|c|c|c|c|c|c|c|}
\hline & \multicolumn{8}{|c|}{ Abortion experiences } \\
\hline & \multicolumn{4}{|c|}{ All women who ever experienced abortion } & \multicolumn{4}{|c|}{$\begin{array}{l}\text { Women who experienced abortions in the } \\
\text { previous five years }\end{array}$} \\
\hline & $\begin{array}{l}\text { Auranga- } \\
\text { bad }\end{array}$ & Jalna & Tonk & Bundi & $\begin{array}{l}\text { Auranga- } \\
\text { bad }\end{array}$ & Jalna & Tonk & Bundi \\
\hline \multicolumn{9}{|l|}{$\begin{array}{l}\text { Post-abortion morbidity: } \\
\text { Percentage of women by } \\
\text { post-abortion morbidity } \\
\text { experienced }\end{array}$} \\
\hline Post-abortion morbidity ${ }^{1}$ & 39.6 & 55.0 & 16.7 & 13.0 & 39.3 & 59.2 & 20.7 & 13.3 \\
\hline None & 60.4 & 45.0 & 83.3 & 87.0 & 60.7 & 40.8 & 79.3 & 86.7 \\
\hline Backache & 18.8 & 39.8 & 3.3 & 3.1 & 19.0 & 44.9 & 6.9 & 5.0 \\
\hline Abdominal pain/cramps & 18.8 & 30.4 & 4.4 & 6.9 & 16.7 & 34.7 & 6.9 & 5.0 \\
\hline Fatigue and weakness & 22.1 & 32.5 & 8.9 & 3.1 & 17.9 & 33.7 & 10.3 & 3.3 \\
\hline $\begin{array}{l}\text { Persistent bleeding for two } \\
\text { to four weeks }\end{array}$ & 8.4 & 14.7 & 3.3 & 3.8 & 8.3 & 14.3 & 6.9 & 5.0 \\
\hline $\begin{array}{l}\text { Persistent bleeding for more } \\
\text { than four weeks }\end{array}$ & 3.9 & 3.7 & 1.1 & 0.8 & 4.8 & 3.1 & 3.4 & 1.7 \\
\hline Foul smelling discharge & 1.9 & 5.8 & 0.0 & 0.0 & 0.0 & 7.1 & 0.0 & 0.0 \\
\hline High-grade fever & 5.8 & 6.3 & 2.2 & 0.8 & 2.4 & 4.1 & 6.9 & 1.7 \\
\hline Dizziness & 8.4 & 16.2 & 4.4 & 0.8 & 10.7 & 18.4 & 3.4 & 1.7 \\
\hline Uterus perforation/rupture & 0.0 & 0.0 & 1.1 & 0.8 & 0.0 & 0.0 & 3.4 & 1.7 \\
\hline Irregular menstruation & 0.6 & 3.1 & 1.1 & 2.3 & 0.0 & 2.0 & 3.4 & 5.0 \\
\hline Psychological symptoms & 0.6 & 2.6 & 0.0 & 0.0 & 0.0 & 3.1 & 0.0 & 0.0 \\
\hline \multicolumn{9}{|l|}{ Care for complications } \\
\hline Sought care & 49.2 & 51.4 & $*$ & * & 51.5 & 56.9 & * & * \\
\hline $\begin{array}{l}\text { Complications affected } \\
\text { the ability to do regular } \\
\text { household work }\end{array}$ & 72.1 & 75.2 & * & * & 69.7 & 77.6 & * & $*$ \\
\hline $\begin{array}{l}\text { Hospitalized for } \\
\text { complications }\end{array}$ & 21.3 & 15.2 & * & * & 18.2 & 12.1 & * & $*$ \\
\hline $\begin{array}{l}\text { Number who experienced } \\
\text { complications }\end{array}$ & 61 & 105 & 15 & 17 & 33 & 58 & 6 & 8 \\
\hline
\end{tabular}

Cont'd on next page... 
Appendix 3: (Cont'd)

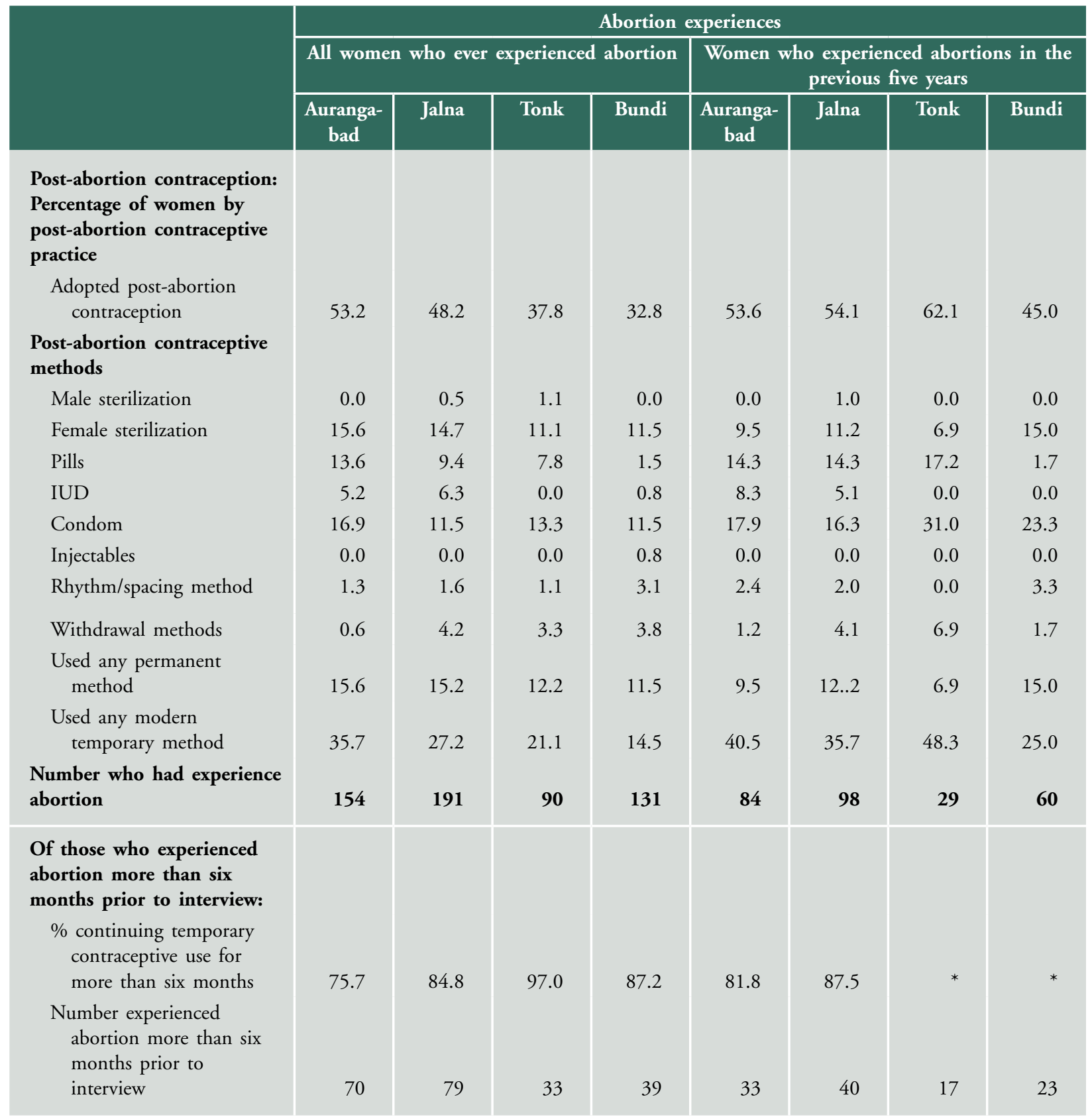

*Percentage not shown, based on fewer than 25 unweighted cases.

${ }^{1}$ Multiple responses possible.

23 women from Maharashtra who had ever successfully terminated a pregnancy by themselves or with help from a relative or friend, and 1 woman from Maharashtra who had done so in the last 5 years were excluded. 


\section{Appendix 4}

Quality of abortion care excludes previous unsuccessful attempts

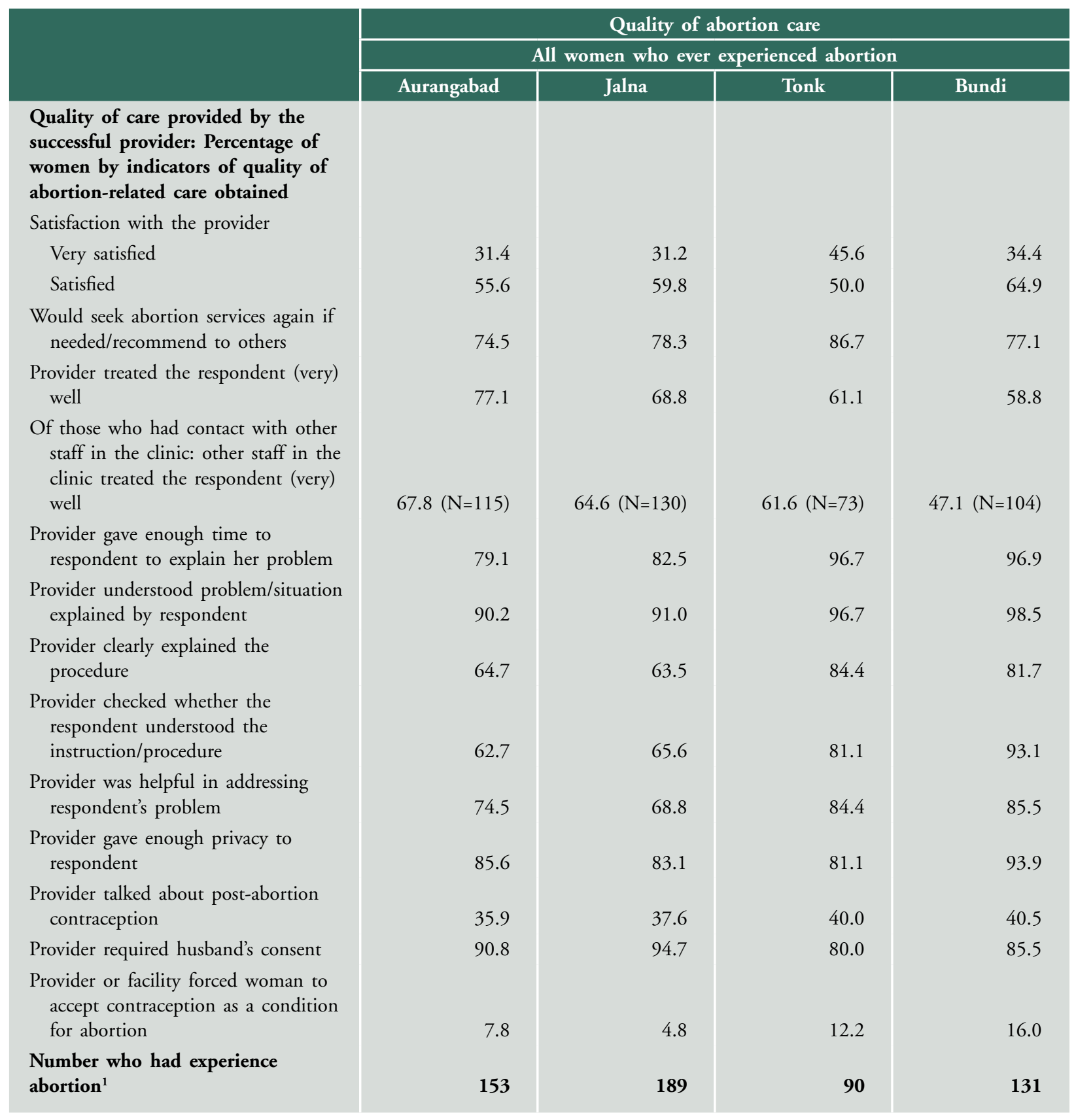

Note: ${ }^{1}$ Excludes 3 women whose abortion was conducted by themselves, a family member or friend. 


\section{Population Council}

South \& East Asia-Regional Office

Zone 5-A, Ground Floor

India Habitat Centre

Lodi Road

New Delhi 110 003, India 